\title{
A Climatology of Northern Hemisphere Blocking
}

\author{
DAVID BARRIOPEDRO AND RiCARDO GARCÍA-HERRERA \\ Departamento de Física de la Tierra II, Facultad Ciencias Físicas, Universidad Complutense de Madrid, Madrid, Spain \\ ANTHONY R. LUPO \\ Departament of Soil, Environmental, and Atmospheric Sciences, University of Missouri-Columbia, Columbia, Missouri \\ EMILIANO HERNÁNDEZ \\ Departamento de Física de la Tierra II, Facultad Ciencias Físicas, Universidad Complutense de Madrid, Madrid, Spain
}

(Manuscript received 17 December 2004, in final form 6 September 2005)

\begin{abstract}
In this paper a 55-yr (1948-2002) Northern Hemisphere blocking climatology is presented. Traditional blocking indices and methodologies are revised and a new blocking detection method is designed. This algorithm detects blocked flows and provides for a better characterization of blocking events with additional information on blocking parameters such as the location of the blocking center, the intensity, and extension. Additionally, a new tracking procedure has been incorporated following simultaneously the individual evolution of blocked flows and identifying coherently persistent blocked patterns.

Using this method, the longest known Northern Hemisphere blocking climatology is obtained and compared with previous studies. A new regional classification into four independent blocking sectors has been obtained based on the seasonally preferred regions of blocking formation: Atlantic (ATL), European (EUR), West Pacific (WPA), and East Pacific (EPA). Global and regional blocking characteristics have been described, examining their variability from the seasonal to interdecadal scales.

The global long-term blocking series in the North Hemisphere showed a significant trend toward weaker and less persistent events, as well as regional increases (decreases) in blocking frequency over the WPA (ATL and EUR) sector. The influence of teleconnection patterns (TCPs) on blocking parameters is also explored, being confined essentially to wintertime, except in the WPA sector. Additionally, regional blocking parameters, especially frequency and duration, are sensitive to regional TCPs, supporting the regional classification obtained in this paper. The ENSO-related blocking variability is evident in blocking intensities and preferred locations but not in frequency. Finally, the dynamical connection between blocking occurrence and regional TCPs is examined through the conceptual model proposed by Charney and DeVore. Observational evidence of a dynamical link between the asymmetrical temperature distributions induced by TCPs and blocking variability is provided with a distinctive contrast "warm ocean/cold land" pattern favoring the blocking occurrence in winter. However, the conceptual model is not coherent in the WPA sector, suggesting different blocking mechanisms operating in this sector.
\end{abstract}

\section{Introduction}

During the last several decades some studies have applied subjective blocking criteria based on surface and midtroposphere observations of typical blocking flow configurations. Following the traditional Rex

Corresponding author address: R. García-Herrera, Dpto. Física de la Tierra II, Facultad Ciencias Físicas, Universidad Complutense de Madrid, Ciudad Universitaria, 28040 Madrid, Spain. E-mail: rgarciah@fis.ucm.es (1950a) criterion, a blocking event can be identified through a split-flow regime in the middle troposphere as a double jet detectable over more than $45^{\circ}$ in longitude and persisting for more than 10 days (Fig. 1). Since then, there have been modifications to the original Rex definition, demanding lower durations or extensions (Treidl et al. 1981) as well as new restrictions in latitude location (White and Clark 1975) to exclude semipermanent subtropical anticyclones.

Recently, numerous criteria have been proposed in order to identify objectively atmospheric blocked flows. 
a

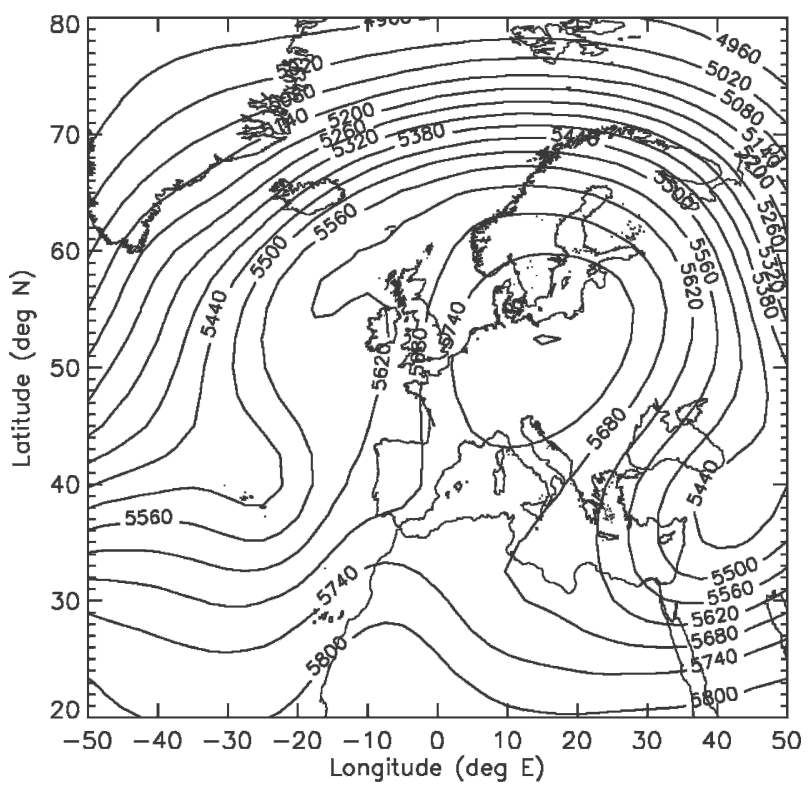

b

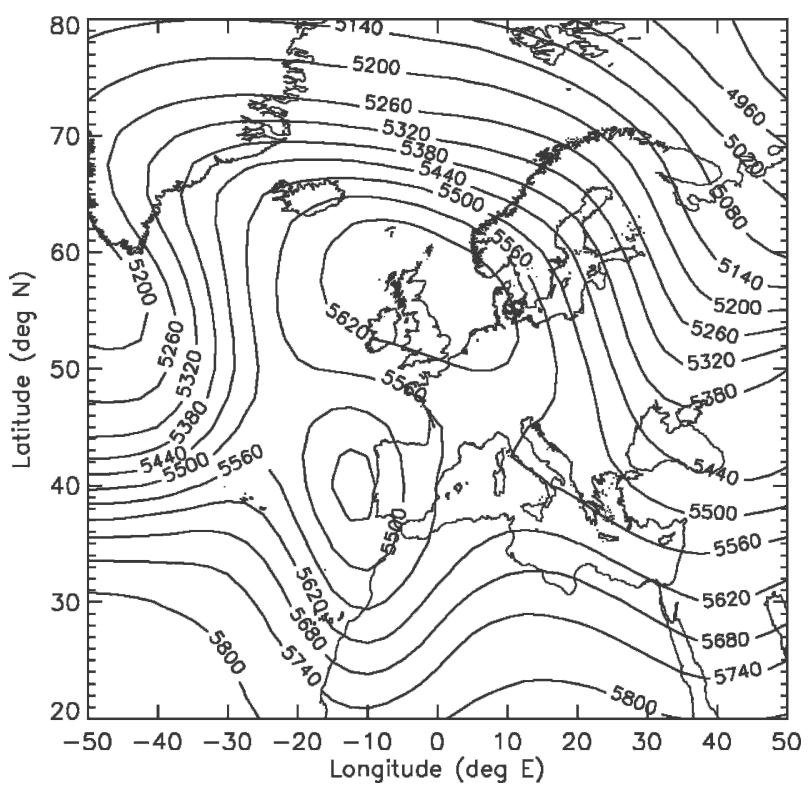

FIG. 1. The 500-hPa height field showing typical blocking patterns: (a) $\Omega$-block (6 Mar 1948) and (b) split-flow block (23 Dec 1948).

Most of them were based on zonal flow indices computed from meridional height gradients at the middle troposphere (Lejenäs and Øakland 1983, hereafter LO83; Tibaldi and Molteni 1990, hereafter TM90; Tibaldi et al. 1997; Trigo et al. 2004). Other methodologies detected blocking events as positive height anomalies at the midtroposheric flow persisting for several days (Charney et al. 1981; Dole and Gordon 1983) or from normalized indices based on daily height pro- jections over mean blocking patterns (Liu 1994; Renwick and Wallace 1996). The most recent methodologies combine traditional subjective and objective criteria, as those used by Lupo and Smith (1995, hereafter LS95) or Wiedenmann et al. (2002, hereafter WI02), or use quantities derived from dynamical properties related to blocking patterns, such as the meridional potential temperature $(\theta)$ gradient on a potential vorticity (PV) surface representative of the tropopause (Pelly and Hoskins 2003), or negative anomalies of vertically integrated potential vorticity within the $500-150-\mathrm{hPa}$ layer (Schwierz et al. 2004).

As a result, several long-term studies focused on North Hemisphere blocking events have been previously published (Rex 1950a,b; LO83; Dole and Gordon 1983; TM90; Tibaldi et al. 1994; LS95; WI02). However, some of them were confined to certain regions or limited to single seasons. Moreover, the behavior of the North Hemisphere blocking has been traditionally described in terms of frequency, duration, and favored occurrence regions, not considering other characteristics such as genesis location, intensity, and size.

On the other hand, there are not many studies addressing long-term blocking variability, especially at interdecadal scales (e.g., Chen and Yoon 2002). Some authors have reported that blocking occurrence may be affected by North Hemisphere large-scale patterns such as the North Atlantic Oscillation (NAO) (e.g., Shabbar et al. 2001). The relationship between blocking and the El Niño-Southern Oscillation (ENSO), however, has been widely discussed (Renwick and Wallace 1996; Watson and Colucci 2002; Mokhov and Tikhonova 2000; WI02). Nevertheless, this linkage has been derived for certain regions or single seasons and the ENSO-related variability, if any, has not been clearly established.

This paper has three objectives: (i) to design an objective automated methodology to provide a complete characterization of single blocked flows as well as a tracking algorithm to identify persistent blocking patterns, (ii) to obtain the longest record of Northern Hemisphere blocking occurrences and parameters providing a robust long-term climatology, and (iii) to examine the blocking variability (from interannual to interdecadal time scales) and the role played by the main North Hemisphere teleconnection patterns (TCPs) and ENSO.

The paper is organized as follows: the data and a description of the automated method are described in section 2. In the next section, the 55-yr climatology of blocking parameters is presented and compared with the results obtained in previous studies. The long-term blocking variability and its connection with the main 
regional and global low-frequency TCPs are presented in section 4. In section 5, these results are discussed and interpreted in the context of blocking theories. Finally, the main conclusions are summarized.

\section{Data and detection algorithm design}

The 55-yr record (1948-2002) of daily 500-hPa height geopotential fields at 0000 UTC over a $2.5^{\circ}$ latitude by $2.5^{\circ}$ longitude grid for the whole Northern Hemisphere, extracted from the National Centers for Environmental Prediction-National Center for Atmospheric Research (NCEP-NCAR) reanalysis dataset, was used (Kalnay et al. 1996; Kistler et al. 2001).

\section{a. Blocking index}

Since blocking patterns are characterized by an appreciable mass difference between high and middle latitudes (Namias and Clapp 1951; Austin 1980; Treidl et al. 1981) and anomalous easterly winds, the blocking index used here is an adapted version of the TM90 index (see Trigo et al. 2004), which is based on the original criterion proposed by LO83. According to the LO83 criterion, a blocking event can be identified when the averaged zonal index (referred to hereafter as LO) computed as the 500-hPa height difference between $40^{\circ}$ and $60^{\circ} \mathrm{N}$, is negative over $30^{\circ}$ in longitude and during five or more days (Fig. 2a). However, TM90 noted that cutoff lows displaced poleward could also yield negative LO values. To exclude these, TM90 demanded an additional negative height gradient northward of $60^{\circ} \mathrm{N}$. In agreement with that, a blocking event was detected when at least three consecutive longitudes appeared as blocked during at least five days. Following the TM90 methodology, two 500-hPa height geopotential gradients (GHGN and GHGS) have been simultaneously computed for each longitude and for each day of study over the North Hemisphere in agreement with expression (1):

$$
\begin{aligned}
\mathrm{GHGN} & =\frac{Z\left(\lambda, \phi_{N}\right)-Z\left(\lambda, \phi_{0}\right)}{\phi_{N}-\phi_{0}}, \\
\mathrm{GHGS} & =\frac{Z\left(\lambda, \phi_{0}\right)-Z\left(\lambda, \phi_{S}\right)}{\phi_{0}-\phi_{S}} \\
\phi_{N} & =77.5^{\circ} \mathrm{N}+\Delta \\
\phi_{0} & =60.0^{\circ} \mathrm{N}+\Delta \\
\phi_{S} & =40.0^{\circ} \mathrm{N}+\Delta \\
\Delta & =-5.0^{\circ},-2.5^{\circ}, 0.0^{\circ}, 2.5^{\circ}, 5.0^{\circ},
\end{aligned}
$$

where $Z(\lambda, \phi)$ is the 500 -hPa height geopotential at latitude $\phi$ and longitude $\lambda$. GHGS is proportional to the zonal geostrophic wind component and provides a mea-

\section{a}

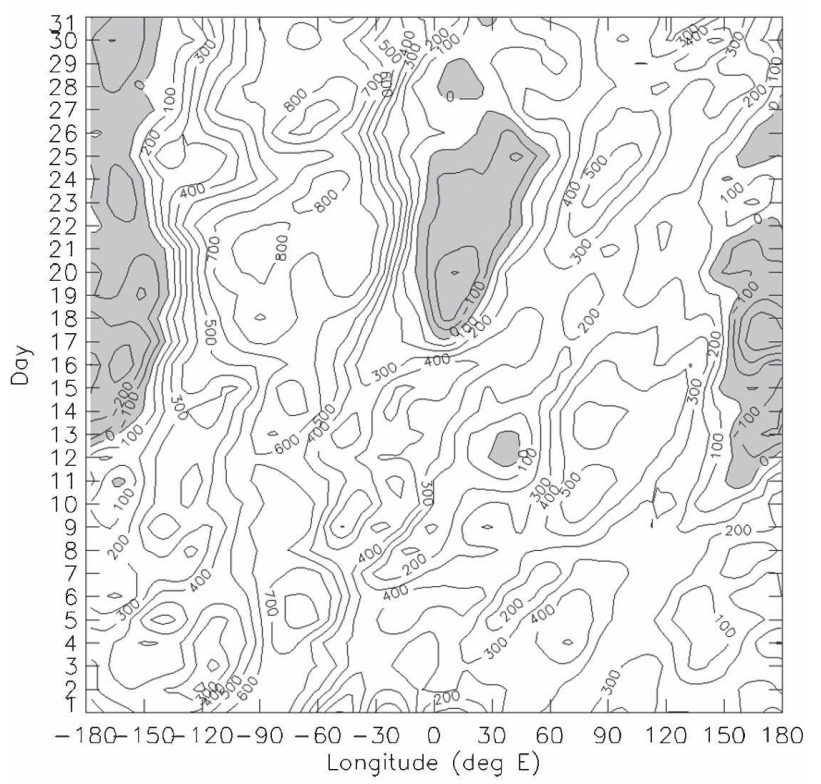

b

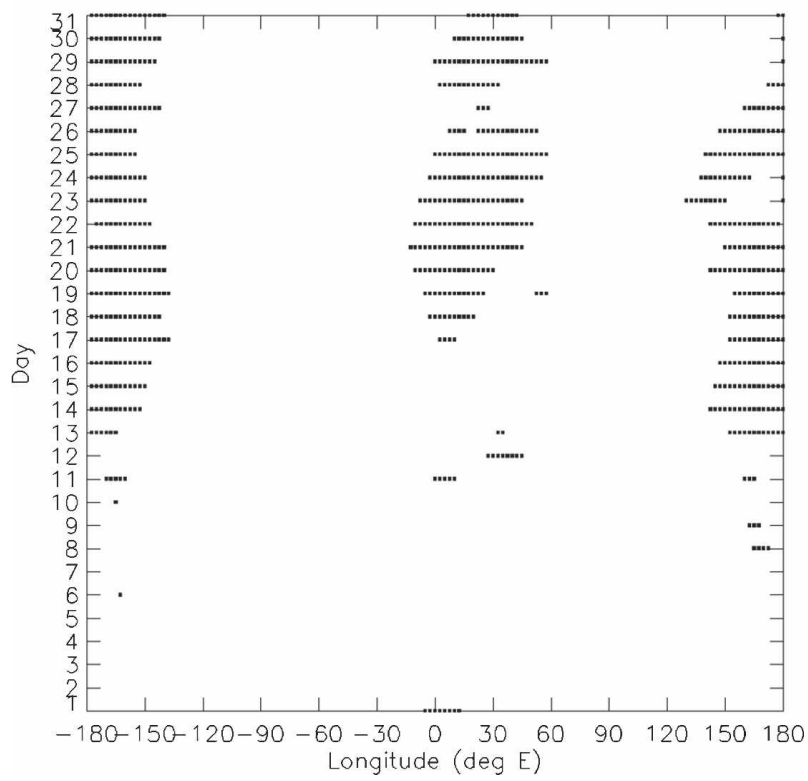

FIG. 2. Longitude-time Hovmöller diagrams for January 1950 displaying (a) the LO index as defined by LO83 and (b) the modified version of the TM90 index used in this paper. Shaded areas indicate blocked longitudes.

sure of the zonal flow intensity for each longitude, while the GHGN gradient is imposed in order to exclude nonblocked flows. This new version of the TM90 index is based on the availability of higher resolution for the NCEP-NCAR gridded data and latitudinal frequency distribution of blocking episodes than that used by Treidl et al. (1981) (Trigo et al. 2004). Thus, an arbitrary longitude is considered blocked when both 


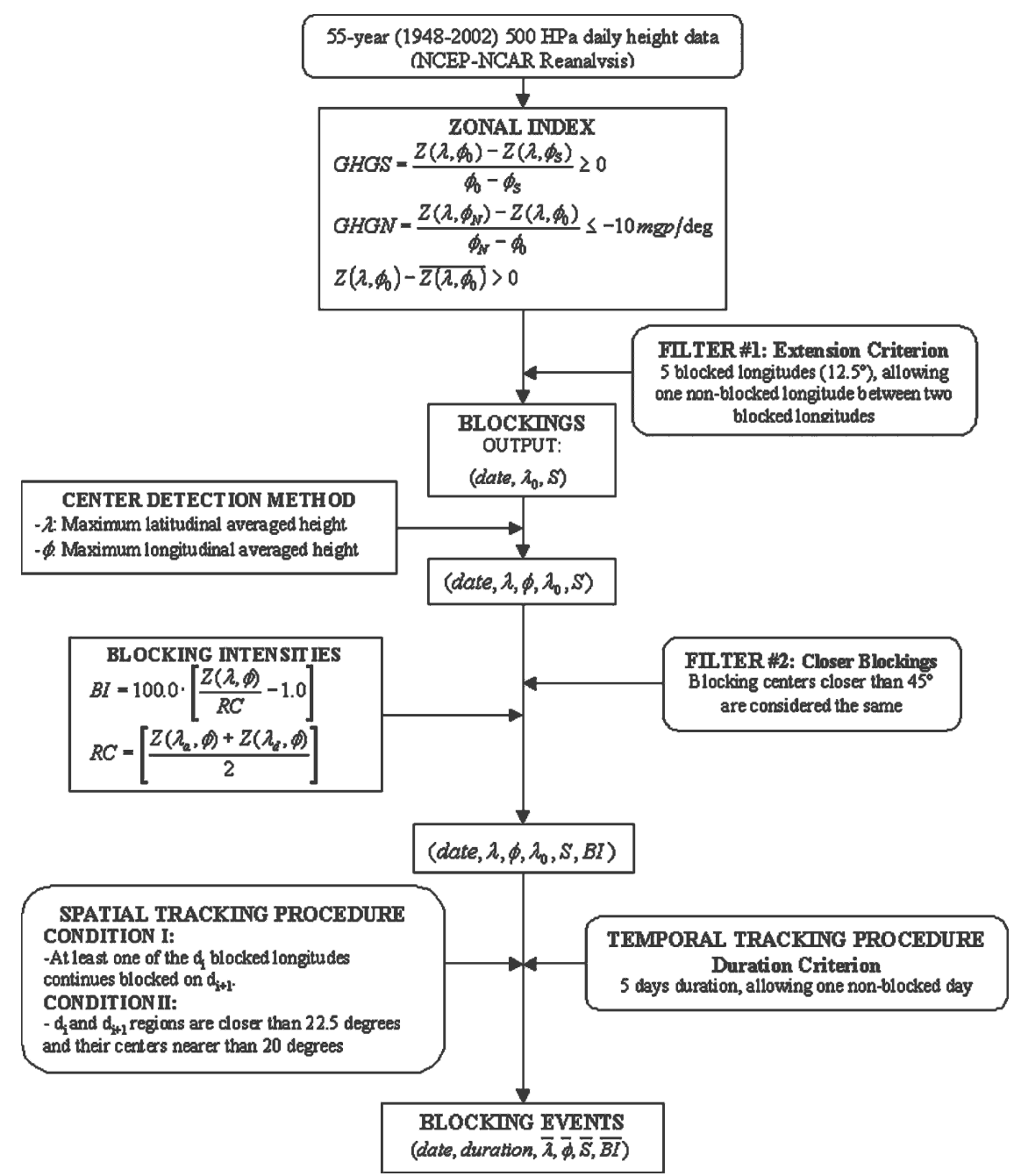

FIG. 3. Schematic of the automated blocking detection method.

GHGN and GHGS verify the condition expressed by Eq. (3) for at least one of the five $\Delta$ values and simultaneously the $\phi_{0}$ height anomaly is positive (see Fig. $2 \mathrm{~b}$ for an example). This requirement minimizes the problem of identifying cutoff lows as blocked flows. Also, the procedure incorporates better spatial resolution and more blocking opportunities by allowing five $\Delta$ values instead of the three proposed by TM90;

$$
\begin{gathered}
\text { GHGN }<-10 \mathrm{gpm} /{ }^{\circ} \text { lat } \\
\text { GHGS }>0 \\
Z\left(\lambda, \phi_{0}\right)-\overline{Z\left(\lambda, \phi_{0}\right)}>0 .
\end{gathered}
$$

\section{b. Automated single blocking detection}

Figure 3 summarizes the steps followed in the detection of blocking events. Since blocking anticyclones are large-scale systems, a blocking pattern can be assumed when several adjacent longitudes are simultaneously blocked. The principle of the automated blocking method is then based on the detection of contiguous blocked longitudes persisting for several days. The blocked region extension criterion in automated methodologies has ranged from 7.5 (Verdecchia et al. 1996; Trigo et al. 2004) to $18.75^{\circ}$ (TM90). After testing the blocking index, five $\left(12.5^{\circ}\right)$ or more contiguous longitudes were required to assure that a blocking pattern exists, but allowing one nonblocked longitude between two blocked longitudes. This additional condition is imposed in order to include those blocking patterns showing nonblocked longitudes under an anticyclone area. Thus, in agreement with Verdecchia et al. (1996) and Tibaldi et al. (1997), three consecutive blocked longitudes can sometimes be enough for defining a blocking pattern. By applying the aforementioned criteria, 
blocking anticyclones were initially detected and characterized by the date of occurrence, the first eastern blocked longitude $\left(\lambda_{0}\right)$, and their extension $(S)$, evaluated as the number of blocked longitudes.

\section{c. Center detection}

Unlike previous methodologies, the detection process incorporates a new procedure to detect the center of blocking events. The blocking center is assumed to be the maximum height grid point within the closed or quasi-closed region of anticyclonic flow. This new parameter provides a better characterization of the blocked flow and a useful tool to track the blocking evolution.

A preliminary analysis showed that the longitude of the blocking center is not always confined within the blocked region (defined by the adjacent blocked longitudes), especially when an $\Omega$-block occurs (see Fig. 4). Under this configuration, blocked longitudes sometimes can extend slightly eastward and/or westward of the blocking center showing small negative or near zero GHGS values. Since the blocking center should be located in the blocked region, a latitude-longitude box centered within the blocked region was constructed. The longitude limits extend $5^{\circ}$ east (west) of to the first (last) blocked longitude in order to ensure that the block center is included in the box. The latitude thresholds were selected as those northward (southward) of the maximum (minimum) value of $\phi_{S}\left(\phi_{N}\right)$. The method selects those grid points where the averaged height is maximum within the box. Thus, the longitude center is chosen as that longitude within the box with maximum height latitudinally averaged for box limits. Once the blocking longitude is detected, the latitudinal center is that for the selected longitude center displaying the highest longitudinal averaged height value within the box (see Fig. 5 for an example).

\section{d. Blocking intensity}

A blocking intensity index (BI) was also computed following the methodology of LS95 and WI02. This index was obtained by LS95 by normalizing the local maximum height geopotential $Z(\lambda, \phi)$ (here, the blocking center) with a mean contour line, reference contour line ( $\mathrm{RC}$ ), embracing the downstream and upstream troughs. The original index was slightly modified by WI02 as

$$
\begin{aligned}
\mathrm{BI} & =100.0\left[\frac{Z(\lambda, \phi)}{\mathrm{RC}}-1.0\right] \\
\mathrm{RC} & =\left[\frac{Z\left(\lambda_{u}, \phi\right)+Z\left(\lambda_{d}, \phi\right)}{2}\right],
\end{aligned}
$$

a

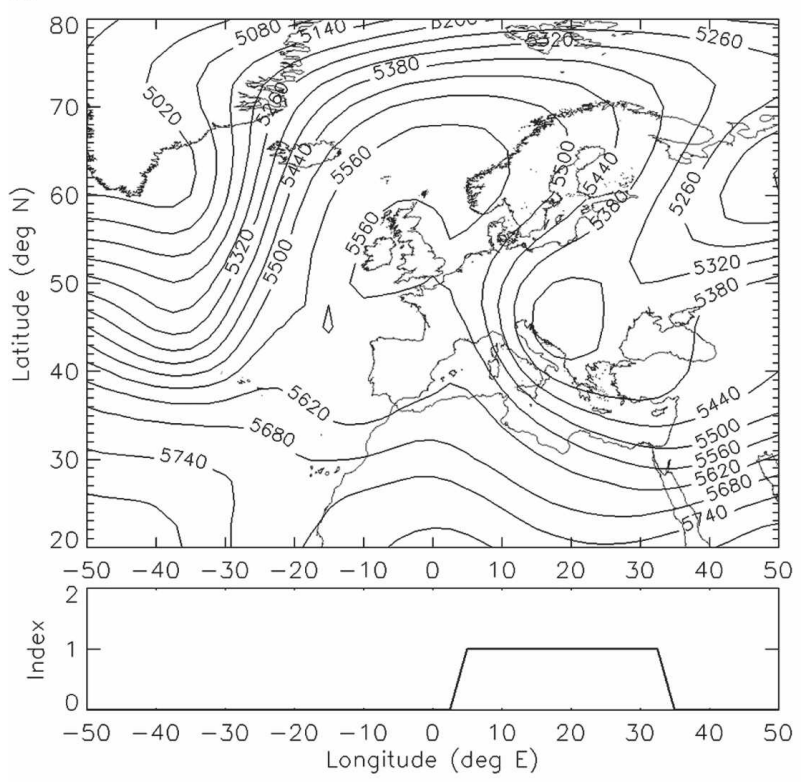

b

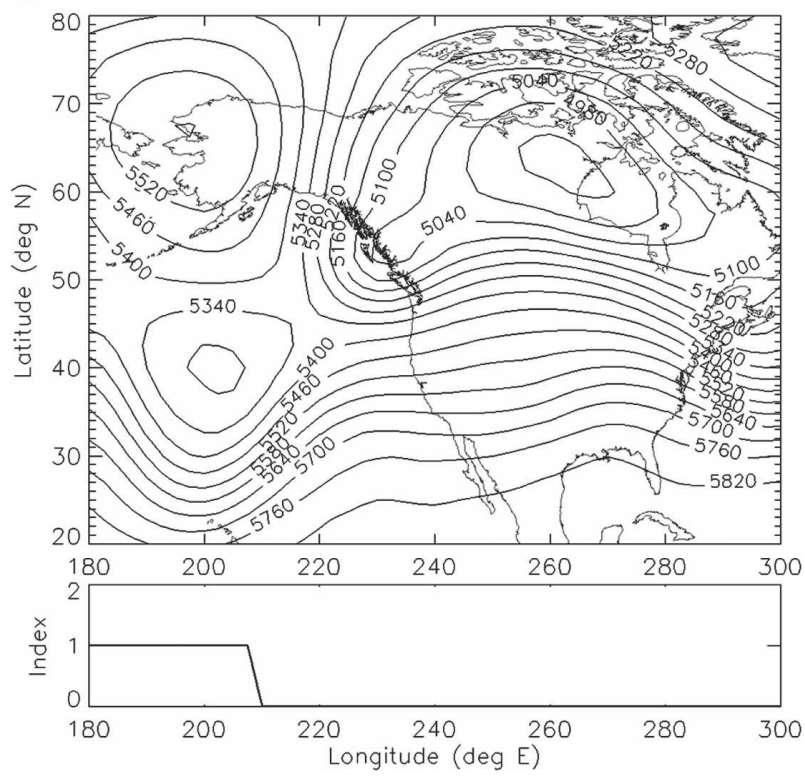

FIG. 4. The 500-hPa blocking patterns: (a) $\Omega$-block (17 Feb) and (b) split-flow block (16 Feb 1986). The graphic below represents the associated blocked region as defined in this paper with $1(0)$ indicating blocked (nonblocked) longitudes.

where that mean line $\mathrm{RC}$ was obtained averaging the lowest trough axis upstream $Z\left(\lambda_{u}, \phi\right)$ and downstream $Z\left(\lambda_{d}, \phi\right)$ heights located at the same latitude of the blocking center. Blocking intensity index values are then proportional to height gradients over the blocked area and provide a measure of the large-scale flow strength (LS95; WI02). The $\lambda_{u}\left(\lambda_{d}\right)$ position was fixed $10^{\circ}$ westward (eastward) of the half-extension from the 
a

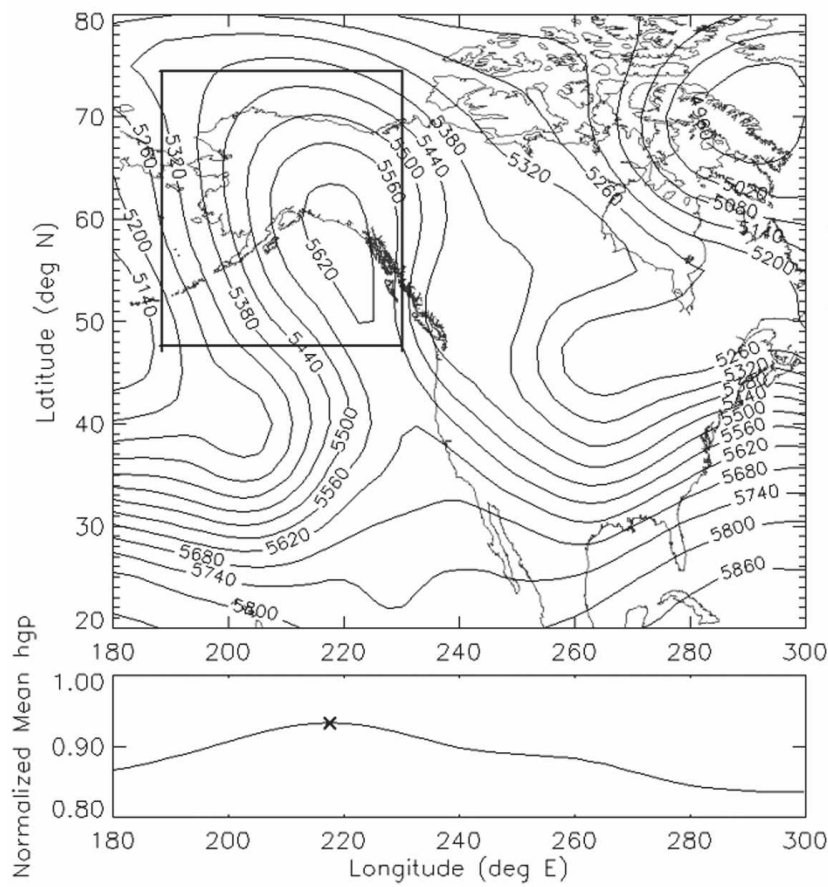

b

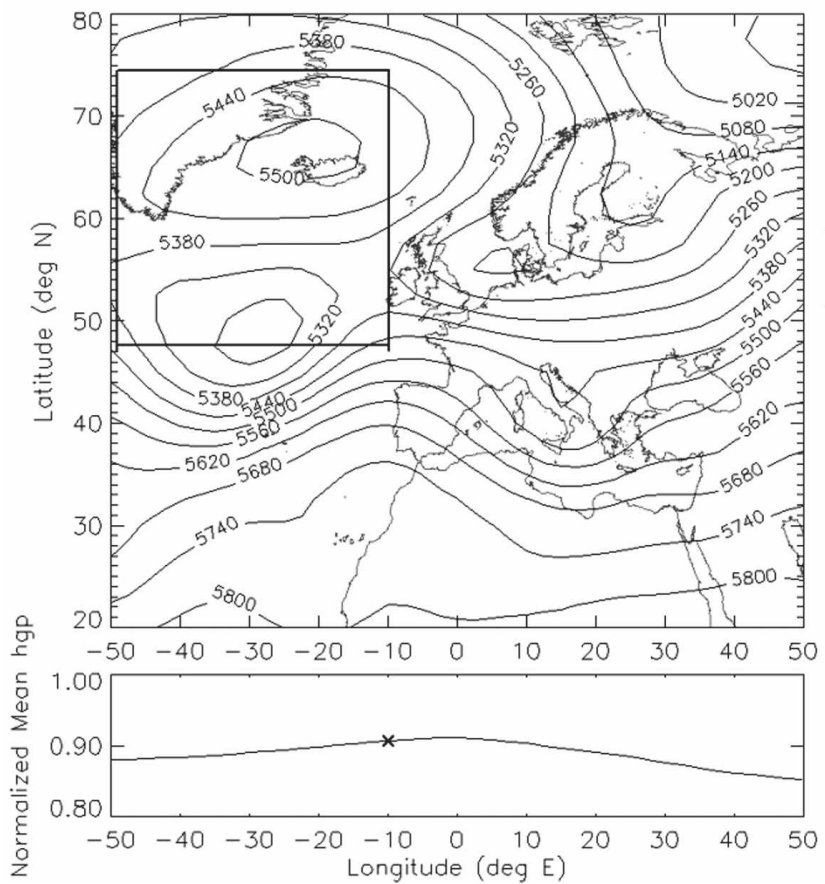

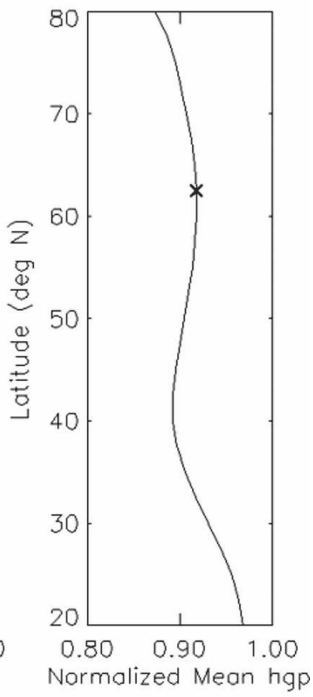

Normalized Mean hgp

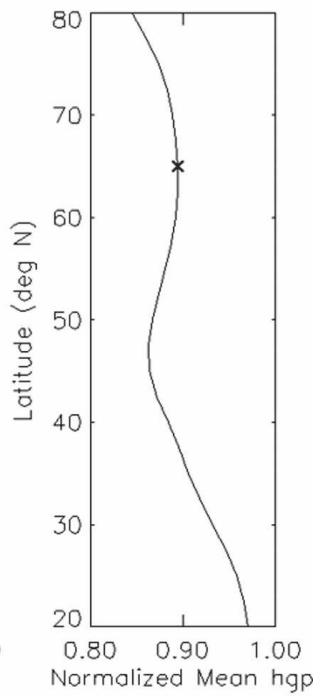

FIG. 5. Blocking patterns and center detection method: (a) $\Omega$-block (11 Feb 1986) and (b) split-flow block (22 Feb 1986). The graphic below (on the right) shows the longitudinal (latitudinal) distribution of the 500-hPa-averaged height for the latitudes (longitudes) within the box. Crosses indicate the blocking center longitude (latitude). 
blocking center in longitude in order to ensure that they are located in the upstream (downstream) of the blocking region.

\section{e. Tracking procedure}

Even though one of the defining characteristics of blocking events is their persistence in time, there is no commonly accepted minimum duration criterion. These have varied between 3 (Elliot and Smith 1949) and 30 days (Treidl et al. 1981), although most authors tend to adopt a value of 5 (Treidl et al. 1981; TM90; d'Andrea et al. 1998) or 10 days (Rex 1950a; Trigo et al. 2004). The designed tracking procedure incorporates both spatial and temporal algorithms.

\section{1) SPAtial ALgORithm}

Although, in agreement with the Rex criterion, most of the simultaneous blocking occurrences showed their centers separated by more than $50^{\circ}$ in longitude, occasionally they were found too close together to be assumed as two independent blocking patterns. In these cases the simultaneously blocked regions appeared to be only one blocking pattern. Thus, those blocking centers closer than $45^{\circ}$ in longitude and showing blocked regions nearer than $22.5^{\circ}$ were considered the same blocking pattern and the blocking candidate with highest height center value was selected as blocking.

\section{2) Temporal algorithm}

The temporal algorithm can be summarized in four steps, consistent with that of Trigo et al. (2004).

(i) Step 1: The blocked area for each blocking anticyclone on day $d_{i}$ is compared with that of each blocking on day $d_{i+1}$ (blocking candidates). A blocking anticyclone on day $d_{i}$ is detected the next day when at least one of its blocked longitudes continues blocked on $d_{i+1}$. If two or more blocking candidates meet this condition, the blocking with more common blocked longitudes is considered as the following location.

(ii) Step 2: In spite of step 1, a few events with a low number of blocked longitudes did not show a blocked area overlap with any of the next day's blocking longitudes. To include these situations, an event on day $d_{i}$ can be linked to a previously nonassigned $d_{i+1}$ blocking if their blocked areas are closer than $22.5^{\circ}$ longitude and their centers nearer than $20^{\circ}$ longitude.

(iii) Step 3: Following the criterion proposed by Trigo et al. (2004), a nonblocked day is allowed between two blocked days for a given blocking anticyclone.
That means that, if a nonassigned $d_{i}$ blocking is detected on $d_{i+2}$ day, verifying the step-1 or step-2 distance restrictions, they are considered the same blocking. This is also consistent with the LS95 criterion.

(iv) Step 4: In agreement with the most widely accepted criteria, a minimum duration of 5 days is required for blocking events, although, according to the previous step, the blocking could be detected intermittently.

Once blocking episodes were identified, the daily parameters $\lambda, \phi, \lambda_{0}, S$, and BI were averaged for the whole life cycle of each event in order to provide a blocking event characterization. This yields a 55-yr Northern Hemisphere database of blocking events described by the date of initiation, duration, and mean and maximum characteristic values of location (affected region), extension (size), and intensity.

\section{NH blocking characterization}

\section{a. Temporal and spatial distributions}

In the 55-yr period of study, a total of 1514 blocking events were detected over the Northern Hemisphere, giving an annual average of about 27 events. As a consequence, about half of the number of days in any given year were blocked on average over any region of the Northern Hemisphere. Although fewer events were obtained by earlier studies (e.g., Treidl et al. 1981; LO83), this result is close to those reported in the later works, such as WI02, who, using NCEP-NCAR datasets, found an annual frequency of 25 events. Blocking durations here show an exponentially decreasing and long-tailed distribution, while the extension and intensity distributions are almost normally distributed with values in the $5-30$ days, $12.5^{\circ}-60^{\circ}$ and $0.5^{\circ}-5^{\circ}$ ranges, and averages of 9 days, $30^{\circ}$ and $2.5^{\circ}$, respectively. Similar values have been found in previous climatologies (LO83; TM90; Tibaldi et al. 1994; LS95; Colucci and Alberta 1996; WI02), although the average blocking intensity is slightly lower than that obtained by WI02. More importantly, the seasonal distributions are also similar to those found in previous studies with higher occurrences for both blocking events and blocked days during winter and spring seasons and a frequency minimum in summer, as well as greater durations, intensities, and extensions in winter than in summer.

Figure 6a displays the annually averaged frequency of blocked longitude distribution for the whole period. As has been noted extensively in the literature, two main sectors with a higher tendency for blocking can be distinguished, encompassing Euro-Atlantic and Pacific 
a

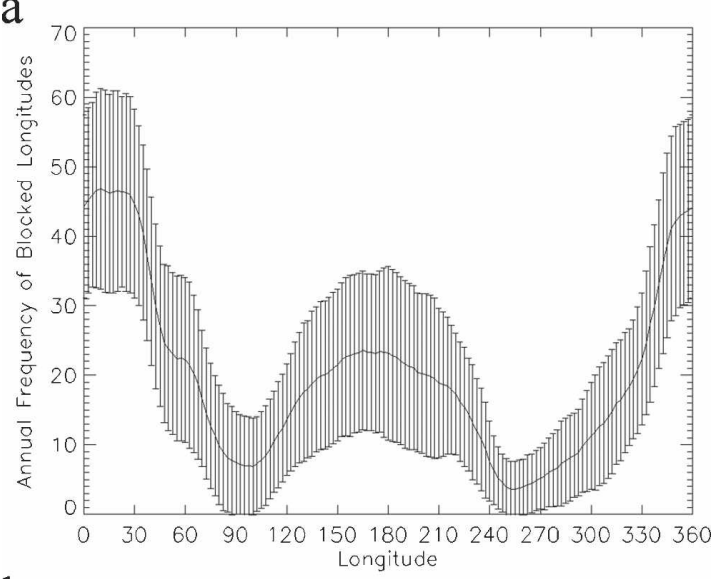

b

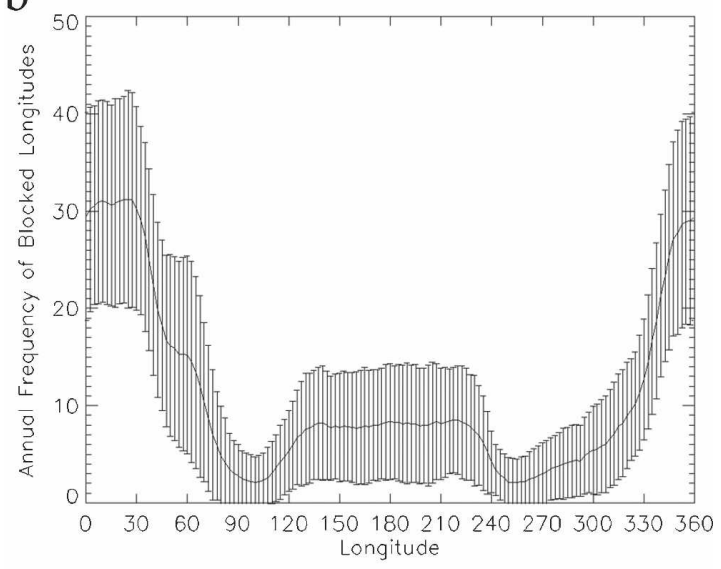

C

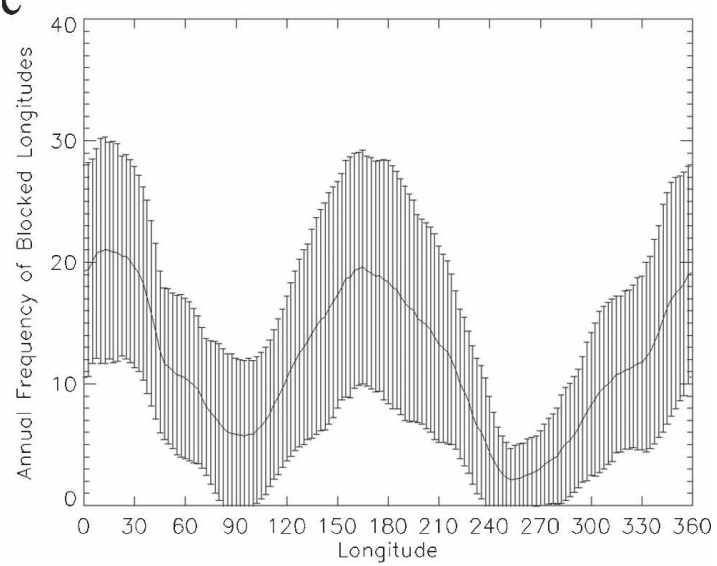

FIG. 6. The 55-yr annually averaged frequency distribution of blocked longitudes and error bars representing the $\sigma$ deviation for (a) all events, (b) events located between $50^{\circ}$ and $60^{\circ} \mathrm{N}$, and (c) events located between $60^{\circ}$ and $70^{\circ} \mathrm{N}$.

regions respectively (Rex, 1950a,b; LO83; Charney et al. 1981; Colucci and Alberta 1996). The Pacific blocking activity extended between $100^{\circ}$ and $240^{\circ} \mathrm{E}$ with a maximum located near the central Pacific $\left(180^{\circ}\right)$ while the Euro-Atlantic counterpart is more prominent, ex- panding from $270^{\circ}$ to $90^{\circ} \mathrm{E}$ with greater frequencies near $10^{\circ} \mathrm{E}$. Both bands of blocked longitudes were separated by regions of preferred zonal flow centered in $100^{\circ}$ and $270^{\circ} \mathrm{E}$. The formation and maintenance of blocking events over these sectors have been dynamically attributed to the storm-track activity occurring downstream of the main continental areas of North America and Asia (Shutts 1983, 1986; Colucci 1985; Konrad and Colucci 1988; Tsou and Smith 1990; LS95). However, there are differences in the spatial distribution for the latitude of the center that have been found over Euro-Atlantic and Pacific regions. Thus, although blocks tended to concentrate within the $60^{\circ}-70^{\circ} \mathrm{N}$ band, Euro-Atlantic blocking was more common southward of $60^{\circ} \mathrm{N}$ (Fig. 6b), while the Pacific activity was enhanced poleward of $60^{\circ} \mathrm{N}$ (Fig. 6c). The Euro-Atlantic (Pacific) maximum frequency northward of the $60^{\circ} \mathrm{N}$ belt was nearly half (twice) that southward of $60^{\circ} \mathrm{N}$. Simultaneously, the preferred regions over the Pacific region are concentrated near $120^{\circ}$ and $210^{\circ} \mathrm{E}$ southward of $60^{\circ} \mathrm{N}$, while the $180^{\circ}$ meridian presented a higher density poleward of $60^{\circ} \mathrm{N}$.

On the other hand, seasonal distributions reveal some differences in the preferred blocked regions (not shown). Thus, it can be inferred that, while the EuroAtlantic and Pacific regions present a reduced blocking activity during the summer, the blocking frequency is substantially enhanced over eastern Europe (EUR) and western Asia. In some previous studies (Treidl et al. 1981; Dole and Gordon 1983; LS95; WI02), this Euro-Asian region, usually referred to as the continental blocking sector, has been considered as a third region for blocking occurrence, independent of Euro-Atlantic and Pacific sectors, and dynamically linked to a third storm track extending along the Mediterranean Sea (e.g., Whittaker and Horn 1981).

To distinguish between genesis and occurrence regions, the first-detected position and the averaged life cycle center location of blocking events have been computed and their distributions simultaneously plotted in Fig. 7. Although blocking formation zones fit well with the preferred blocked areas, confirming that blocking events are essentially quasi stationary, the genesis density was significantly higher than the mean blocking occurrence over the east Atlantic (ATL), suggesting that blocking events originated over the Atlantic sector tend to propagate eastward toward continental regions. A similar behavior was found by Rex (1950b) and LO83. On the other hand, the eastern Pacific genesis maximum was more prominent than its western counterpart, but both display similar occurrence frequencies, inferring a westward displacement of blocking events in the Pacific as well. The Euro-Atlantic (Pa- 
a

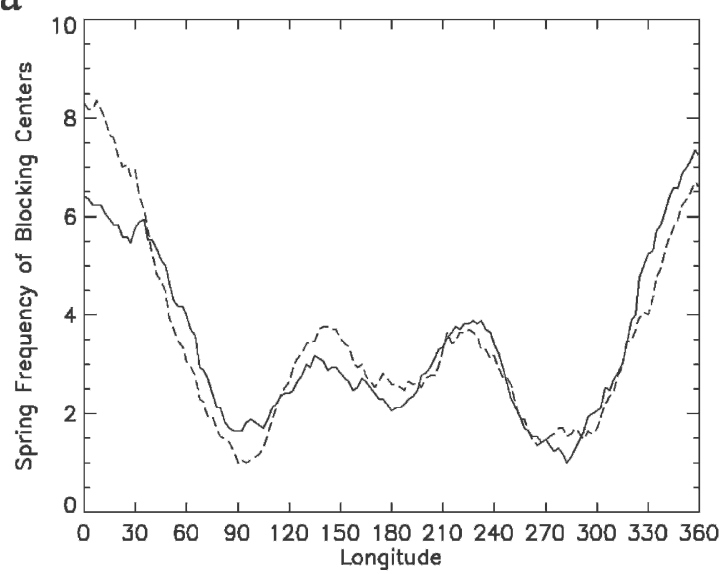

C

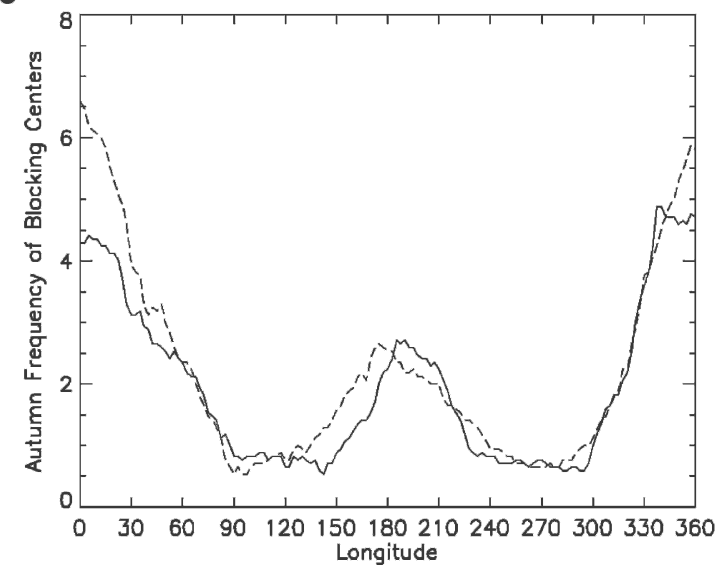

b

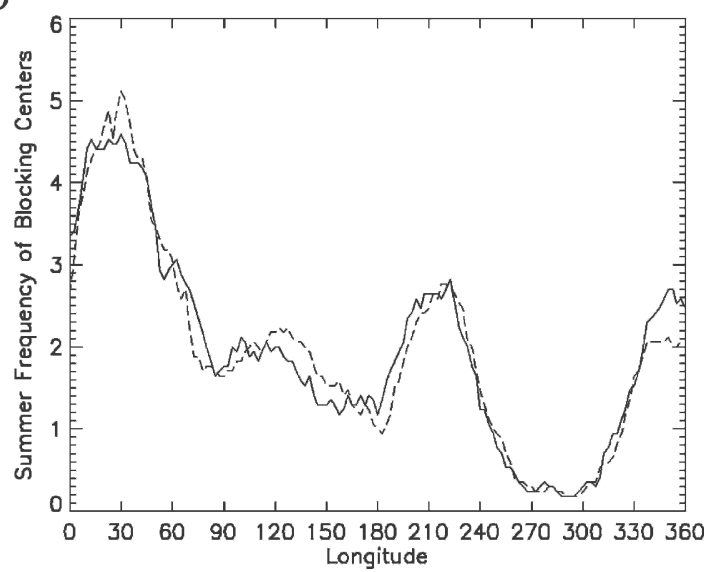

d

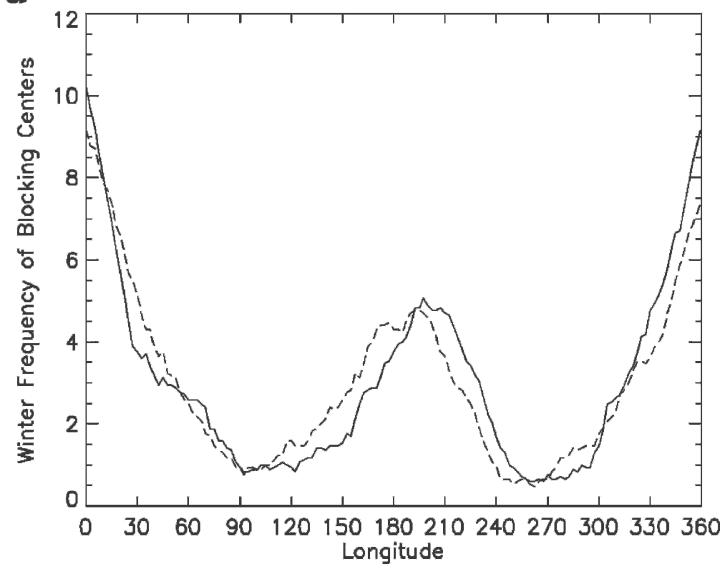

FIG. 7. Seasonal longitudinal frequency distribution of genesis (solid line) and life cycle-averaged (dashed line) blocking center longitude: (a) spring, (b) summer, (c) autumn, and (d) winter.

cific) displacement was more evident in cold (warm) seasons.

Figure 7 suggests two primary blocking episode genesis areas during the cold season: (a) over the central Pacific and the east Atlantic Oceans and (b) near $180^{\circ}$ and $0^{\circ}$. In the warm seasons the central Pacific maximum splits into two genesis bands, downstream $\left(120^{\circ} \mathrm{E}\right)$ and upstream $\left(150^{\circ} \mathrm{W}\right)$ of the Asian and North American continents, respectively. Additionally, the EuroAtlantic activity presented two genesis regions located upstream $\left(10^{\circ} \mathrm{W}\right)$ and downstream $\left(30^{\circ} \mathrm{E}\right)$ of the European continent. Thus, four blocking genesis zones can be identified for the whole North Hemisphere, three of them over the oceanic-continental transition margins and one more at the Euro-Asian frontier. These distributions were also obtained by computing the 55-yr blocking center seasonal distribution (Fig. 8). In cold seasons, events were relatively more frequent over the central Pacific Ocean (the Bering Strait, Aleutian Islands, Othotsk Sea, and Alaska) and over the eastern side of the North Atlantic Ocean (the British Isles, the North Sea, and northwestern Europe), while the blocking activity was reduced over the continental landmasses. However, in spring and summer, blocking centers were displaced poleward and concentrated over the ocean-continent transition margins. Fewer events were found over the Pacific and Atlantic Oceans, while the blocking occurrence is substantially increased upstream and downstream of the main continental masses as well as over Euro-Asia. These results support the existence of four different blocking sectors, suggesting a new regional division. Their domains are shown in Table 1.

\section{b. Regional blocking event characteristics}

The seasonal and regional blocking parameters are shown in Table 2. Examining the climatological averages some differences can be inferred. The seasonal frequencies revealed that blocking events were more common during the spring (winter-spring) for both the EPA, and WPA (ATL and EUR) as well as a minimum 
a

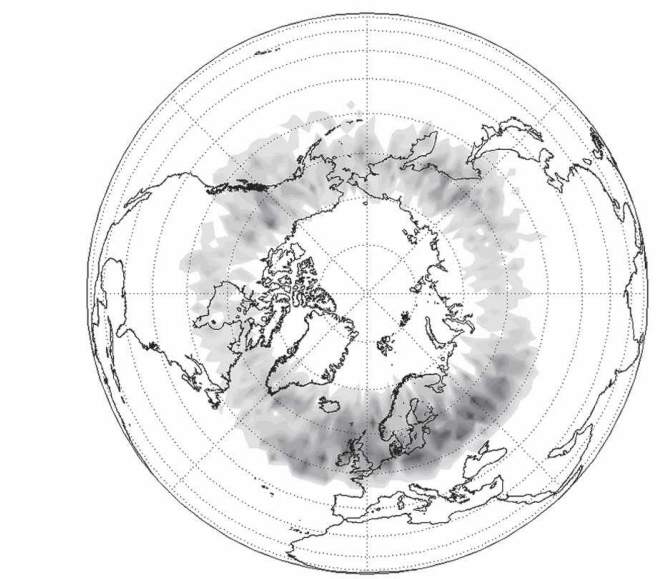

1.02 .03 .04 .05 .06 .07 .08 .09 .010 .11 .12 .13 .14 .15 .16 .17 .18 .19 .20

$\mathrm{C}$

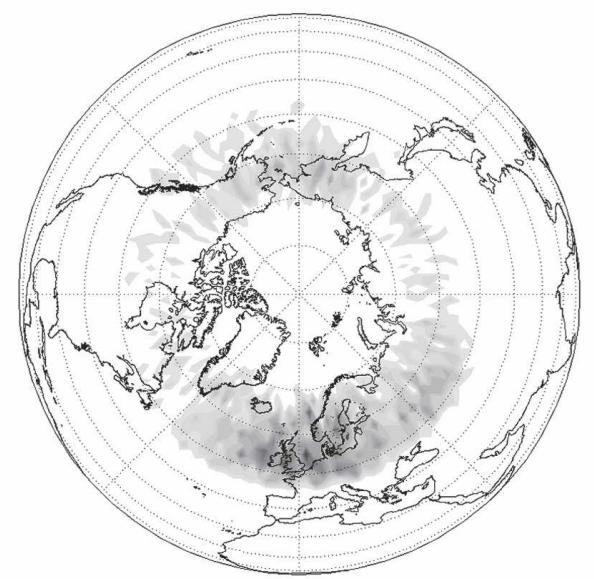

$1.02 .03 .04 .05 .06 .07 .08 .09 .010 .11,12.13 .14 .15,16.17 .18,19.20$ b

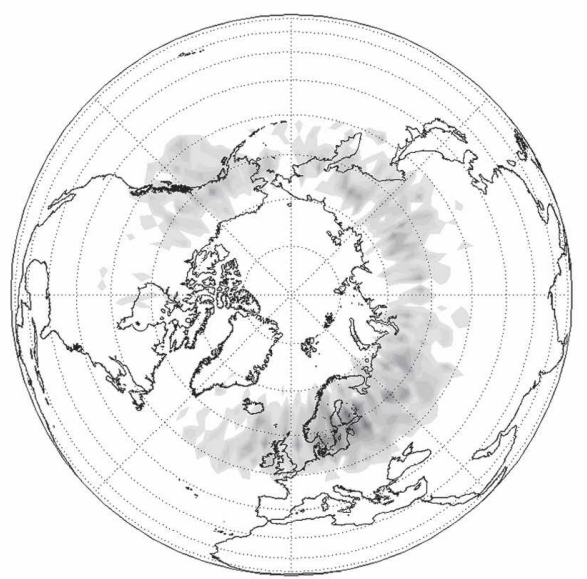

1.02 .03 .04 .05 .06 .07 .08 .09 .010 .11 .12 .13 .14 .15 .16 .17 .18 .19 .20

d

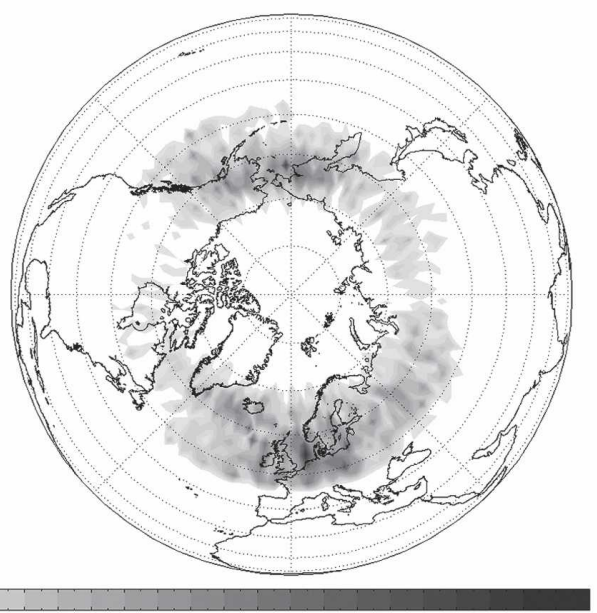

1.02 .03 .04 .05 .06 .07 .08 .09 .010 .11 .12 .13 .14 .15 .16 .17 .18 .19 .20

FIG. 8. Total seasonal frequency of blocking center positions for the 55-yr period: (a) spring, (b) summer, (c) autumn, and (d) winter.

in blocking frequencies during the fall (summer) season. Moreover, those sectors with greater continental surface extension (EUR and WPA) show a secondary occurrence maximum in early summertime. As a result, a marked seasonal cycle was evident over the ATL and EPA sectors, while in the EUR and WPA sectors, and essentially confined to continental surface areas, the variability was less pronounced.

When examining the annual averages, the most persistent episodes were essentially confined to the Euro-

TABLE 1. Blocking sectors defined in this study.

\begin{tabular}{cccccc}
\hline \hline & \multicolumn{2}{c}{ Euro-Atlantic } & & \multicolumn{2}{c}{ Pacific } \\
\cline { 2 - 3 } \cline { 5 - 6 } Sector & ATL & EUR & & WPA & EPA \\
\hline Domain & $\left(100^{\circ} \mathrm{W}, 0^{\circ}\right)$ & $\left(0^{\circ}, 90^{\circ} \mathrm{E}\right)$ & & $\left(90^{\circ} \mathrm{E}, 180^{\circ}\right)$ & $\left(180^{\circ}, 100^{\circ} \mathrm{W}\right)$ \\
\hline
\end{tabular}

pean sector, the difference with Pacific sectors being statistically significant at $p<0.1$ confidence level using the Student's $t$ test. A seasonal breakdown showed more persistent events in the summer over those sectors with high continental presence (EUR and WPA), especially in EUR $(p<0.1)$, whereas during winter long-lived episodes occur over the oceans (ATL and EPA), although differences were not significant at the $p<0.1$ level.

Those events that occurred over the oceanic regions (ATL and EPA) presented significantly greater intensities $(p<0.05)$ in all seasons. Greater block extensions were usually associated with those episodes occurring downstream of the main continents (continent-ocean margins), except in summer and winter when they are located over continents and Pacific sectors, respec- 
TABLE 2. Annual and seasonal mean (columns) of blocking parameters for the Northern Hemisphere and blocking sectors (rows) defined in Table 1. Blocking parameters are referenced in each cell as number of blocking events/duration (days)/BI/S (degrees).

\begin{tabular}{lrcccl}
\hline \hline Region & \multicolumn{1}{c}{ Annual } & Spring & Summer & Fall & Winter \\
\hline ATL & $6.6 / 8.9 / 2.8 / 30.3$ & $2.3 / 8.5 / 2.5 / 29.5$ & $0.7 / 7.0 / 2.1 / 23.8$ & $1.7 / 9.4 / 3.0 / 30.8$ & $1.9 / 9.6 / 3.1 / 33.6$ \\
EUR & $10.6 / 9.2 / 2.4 / 29.1$ & $3.1 / 9.3 / 2.2 / 28.3$ & $2.4 / 8.3 / 1.9 / 25.9$ & $2.4 / 8.9 / 2.8 / 28.8$ & $2.7 / 10.0 / 2.9 / 33.4$ \\
WPA & $5.1 / 8.5 / 2.1 / 31.0$ & $1.7 / 8.7 / 1.8 / 29.2$ & $1.2 / 7.2 / 1.6 / 27.5$ & $0.8 / 8.0 / 2.6 / 32.8$ & $1.4 / 9.7 / 2.7 / 35.3$ \\
EPA & $5.2 / 8.4 / 2.8 / 29.2$ & $1.7 / 8.1 / 2.2 / 27.9$ & $1.0 / 6.7 / 1.8 / 22.9$ & $0.9 / 8.1 / 3.2 / 29.4$ & $1.6 / 10.0 / 3.7 / 34.0$ \\
TOT & $27.5 / 8.8 / 2.5 / 29.8$ & $8.8 / 8.7 / 2.2 / 28.7$ & $5.3 / 7.5 / 1.8 / 25.4$ & $5.8 / 8.8 / 2.9 / 30.1$ & $7.6 / 9.9 / 3.1 / 34.0$ \\
\hline
\end{tabular}

tively, although seasonal extension differences were only statistically significant in summer $(p<0.1)$. The annual variability of intensity and extension was characterized by stronger and greater cold season episodes in all sectors but more evident in ATL and EPA sectors.

In summary, long-lived (high extension) events were relatively more common over the continental regions in the warm seasons and over the oceanic (Pacific) sectors in wintertime, while the strong/weak frequency ratio was higher over the oceanic sectors in all seasons. Additionally, long-lived episodes did not only tend to be more intense as reported by LS95, but also tended to show greater extensions, especially for ATL and EPA sectors $(p<0.01)$.

\section{Interannual and interdecadal variability}

In recent years, long-term blocking variability has been associated with variability of large-scale circulation anomalies (Renwick and Wallace 1996; Shabbar et al. 2001; WI02). However, as discussed previously, the influence of teleconnections has not been completely shown owing to the limited periods and regions used in those previous studies. In this section, the long-term trends and regional variability of blocking parameters related to TCPs are analyzed for the whole North Hemisphere.

\section{a. Series and trends}

For every blocking parameter series global and regional trends have been computed as the slope in the linear regressions versus time. Statistical significance has been assessed using a Student's $t$ test, with significance level $p<0.1$. Table 3 displays the annual significant results computed as the relative change for the 55-yr period.

The 55-yr series in the annually averaged number of blocked days and blocking episodes did not reveal any significant long-term trend for the whole North Hemisphere in agreement with WI02. Breaking down the entire Northern Hemisphere into sectors, the EUR (ATL) sector showed a significant downward trend with a $55-\mathrm{yr}$ decrease of $-17.6 \%(-21.2 \%)$ in blocked days while a linear increase of $57.0 \%$ blocked days was found significant over the WPA sector for the whole period. Examining the series by season, the positive (negative) WPA (ATL) trend was confined to spring (winter), while none of the seasonal EUR series reached any significant change in blocking days.

Examining the long-term variability in the number of blocking events, the annual and spring series in the WPA events also displayed significant upward trends. There were analogous decreases in the number of annual and winter ATL events. These trends are in agreement with those obtained in the number of blocked days, whereas no significant trends were found in EUR events. As a whole, the regional trends over ATL and EUR led to decrease blocked days $(-19.6 \%)$ and events $(-21.0 \%)$ in winter for the entire North Hemisphere, while the upward trend in WPA sector produced a simultaneous increase in the number of spring blocking events $(28.8 \%)$ but not in blocked days.

On the other hand, there was an overall NH longterm change toward less persistent and less intense blocking events. This agrees with the results of Lupo et al. (1997), which showed, using a climate model, that blocking events would be less intense and less persistent in a warmer climate. The global trend in duration was only significant in the EUR sector at the regional level, with an annual decreasing trend of $-17.6 \%$ for the 55 -yr period. As a consequence, while the increased (decreased) number of blocked days in the WPA (ATL) resulted in an increase (decrease) in the number of events, the negative EUR duration trend can be as-

TABLE 3. Relative annual changes (\%) in blocking parameters for the 55-yr period. Significant trends at $p<0.1,0.05$, and 0.01 are shown in italic, bold italic, and bold regular font, respectively.

\begin{tabular}{lccccc}
\hline \hline Region & $\begin{array}{c}\text { Blocking } \\
\text { days }\end{array}$ & $\begin{array}{c}\text { Blocking } \\
\text { events }\end{array}$ & Duration & Intensity & Size \\
\hline ATL & -21.2 & -20.9 & - & -11.6 & $-\mathbf{8 . 8}$ \\
EUR & -17.6 & - & $-\mathbf{1 7 . 6}$ & - & - \\
WPA & $\mathbf{5 7 . 0}$ & $\mathbf{6 2 . 4}$ & - & - & - \\
EPA & - & - & - & -9.8 & 8.8 \\
TOT & - & - & -8.2 & -5.5 & - \\
\hline
\end{tabular}


TABLE 4. The influence of TCPs in regional blocking occurrence computed as the percentage of explained variance from a multiple stepwise regression (in parentheses). TCPs in italic indicate negative correlations. Only significant modes explaining more than $20 \%$ of the total variance are shown.

\begin{tabular}{ccccr}
\hline \hline Region & Spring & Summer & Fall & Winter \\
\hline ATL & - & - & NAO $(23.4 \%)$ & NAO $(44.9 \%)$ \\
EUR & - & - & SCAN $(20.8 \%)$ & SCAN $(30.0 \%)$ \\
WPA & $W P(23.9 \%)$ & - & - & - \\
EPA & - & - & - & $E P(38.3 \%)$ \\
\hline
\end{tabular}

sociated with the simultaneous decrease in blocked days. With regard to blocking intensities, a negative annual trend was observed in the ATL, EUR, and EPA sectors, especially in warm seasons, although only significant over the ATL and EPA sectors. However, unlike the global behavior, WPA blocking intensities tended toward increasing values (not significant).

\section{b. Teleconnection patterns}

To explore blocking variability, the main Northern Hemisphere variability patterns have been included in this study: North Atlantic Oscillation (NAO), East Atlantic (EA), East Atlantic Jet (EAJ), East Atlanticwestern Russia (EAWR), Scandinavian (SCAN), West Pacific (WP), East Pacific (EP), and Pacific-North American (PNA) patterns (Wallace and Gutzler 1981; Barnston and Livezey 1987). Indices obtained from the first rotated empirical orthogonal function (EOF) of 700-hPa fields have been extracted from the Climatic Prediction Center (CPC) at the NOAA Web site (online at http://www.cpc.ncep.noaa.gov). To assess the global ENSO influence on blocking occurrence and compare with those results provided in the literature, a monthly ENSO index has also been obtained from the NOAA CPC Web site, based on a running mean Pacific Ocean basin SST anomaly over the El Niño-3 region $\left(5^{\circ} \mathrm{N}-5^{\circ} \mathrm{S}, 150^{\circ}-90^{\circ} \mathrm{W}\right)$. Monthly series have been annually and seasonally averaged with winter defined as the January-March (JFM) period.

Once the averaged indices have been computed, those values departing from the climatic mean at the 0.5- $\sigma$ level (standard deviations) above (below) are considered as periods in which the pattern remained in positive (negative) phase.

In this section, the influence of the main TCPs on blocking frequency variability has been investigated for every sector at annual and seasonal scales through a multiple stepwise regression. This statistical procedure selects the independent variables to include in a multiple regression model, assuming that some inputs do not have an important explanatory effect on the response due to their multicollinearity. The basic proce- dures involve 1) identifying an initial model from that factor for which the sum of squares due to regression (SSR) is greatest, 2) repeatedly altering the model at the previous step by adding (removing) the predictor variable that significantly (no significantly) increases (reduces) SSR by the greatest (smallest) amount after an $F$-test $(p<0.05)$, and 3$)$ finishing the search when all input variables steps have been included or removed (von Storch and Zwiers 1999). Following this procedure, the role of TCPs was considered relevant when at least one of the independent patterns in the stepwise regression accounted for more than $20 \%$ of blocked days variability. The outstanding loading patterns for each blocking sector and each analyzed period are summarized in Table 4.

The analysis showed that, at annual scales, the TCPs did not have a significant impact on any regional blocking occurrence, with no one accounting for more than $5 \%$ of the variance. As shown below, the role of TCPs was essentially limited to cold seasons, whereas in warm seasons blocking variability was not related to the TCPs.

\section{1) Atlantic SECTOR}

The NAO appeared as the leading variability pattern during autumn and winter, accounting for the $25 \%$ and $45 \%$ of the blocking frequency variance, respectively. Figure 9a shows the wintertime average of blocked days for the positive and negative NAO phases as a function of the longitude. During the negative phase of the $\mathrm{NAO}$, the number of ATL winter (fall) blocking days is 31.7 (21.1), the difference being significant at $p<0.01$ $(p<0.05)$ from those occurring during the positive phase of the NAO of 12.7 (9.2). The duration of blocking events was also sensitive to the NAO phase, although only significant for the winter season. Thus, when the NAO was in the negative phase, blocking events persisted more than 11 days on average, much longer than during the positive phase ( 8 days) ( $p<$ 0.05 ) (see Fig. 10a). These results are in agreement with those obtained by Shabbar et al. (2001). They found $67 \%$ more winter blocking days and greater lifetimes 
a

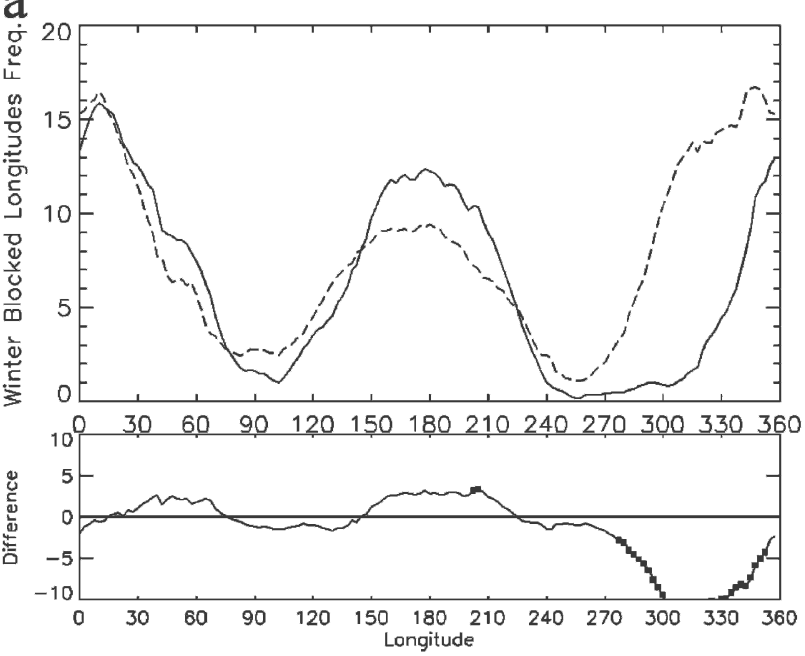

C

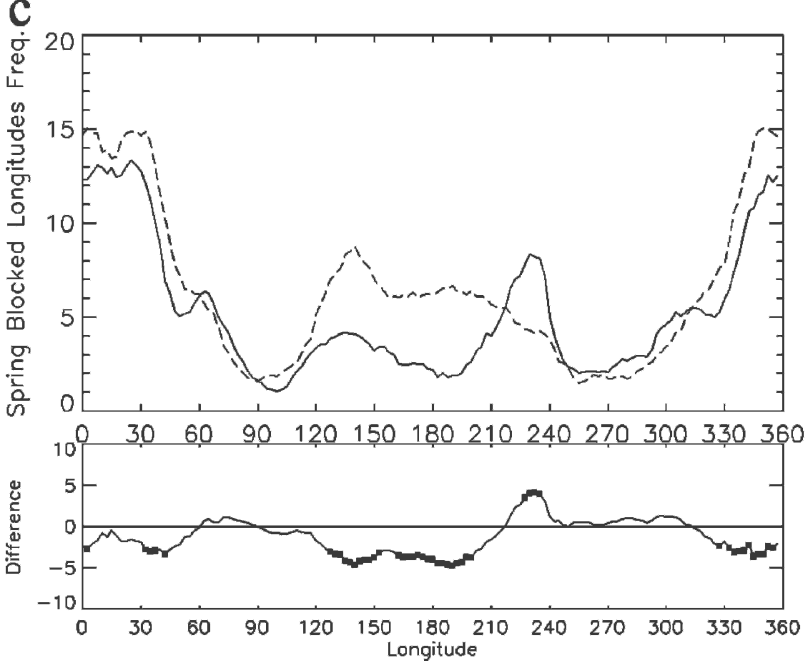

e

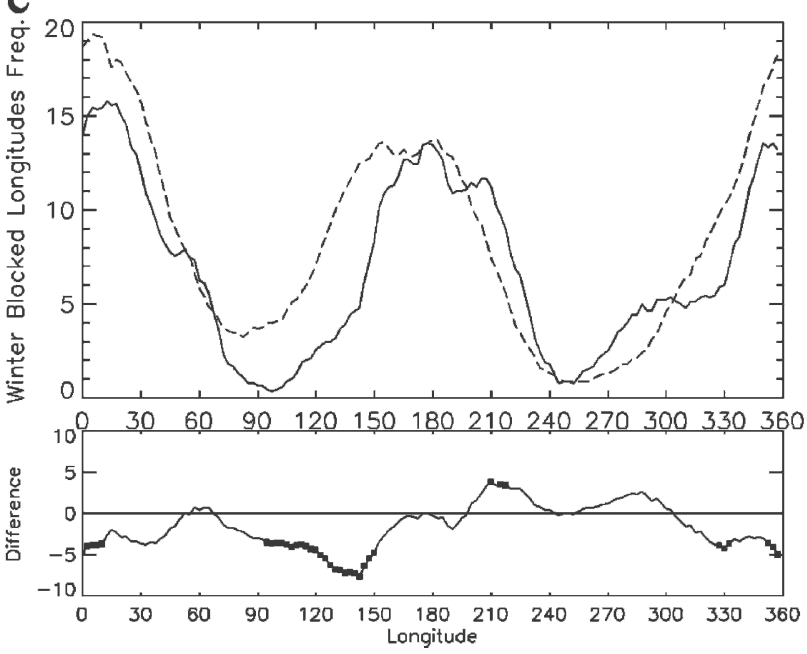

b

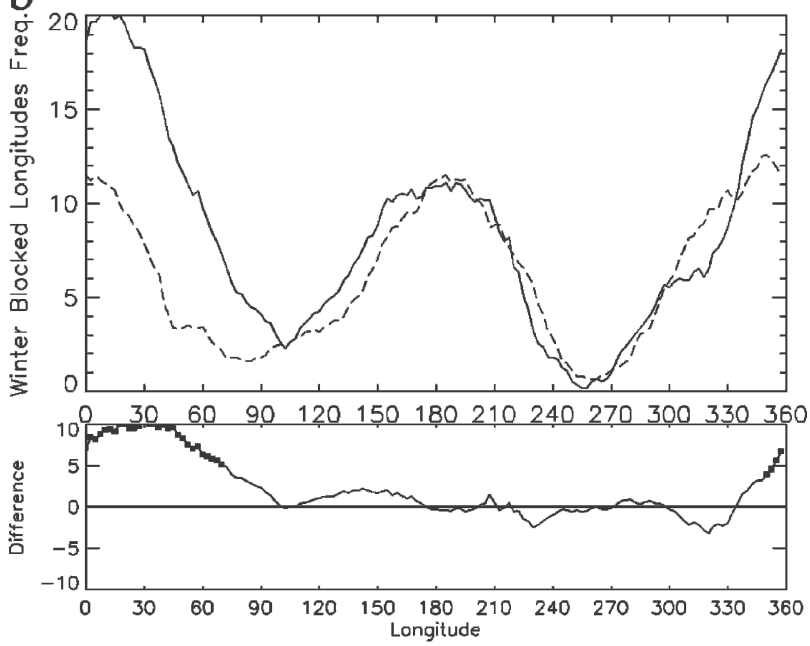

d

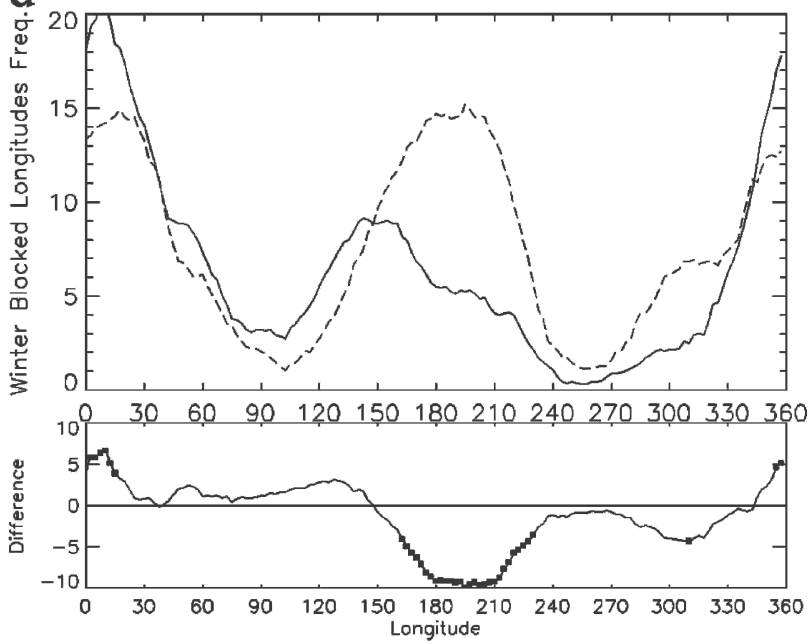

FIG. 9. Frequency composites of blocked days for the positive (solid line) and negative (dashed line) phases of the (a) winter NAO, (b) winter SCAN, (c) spring WP, (d) winter EP, and (e) winter ENSO. The graphics below display frequency differences between the positive and negative phases with dark points indicating significant differences at the $p<0.01$ level. 
a

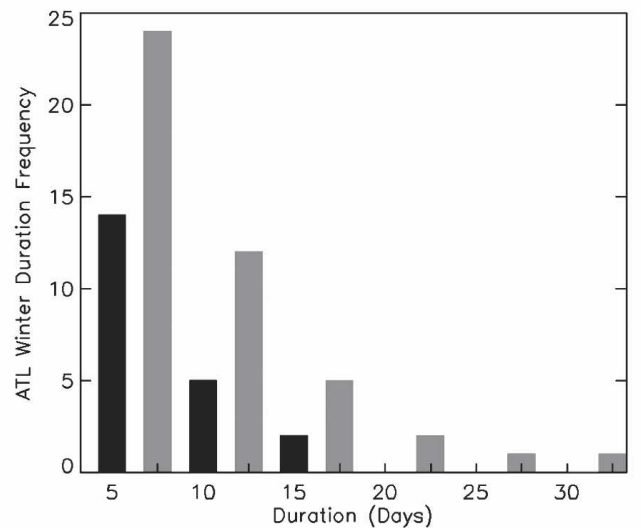

C

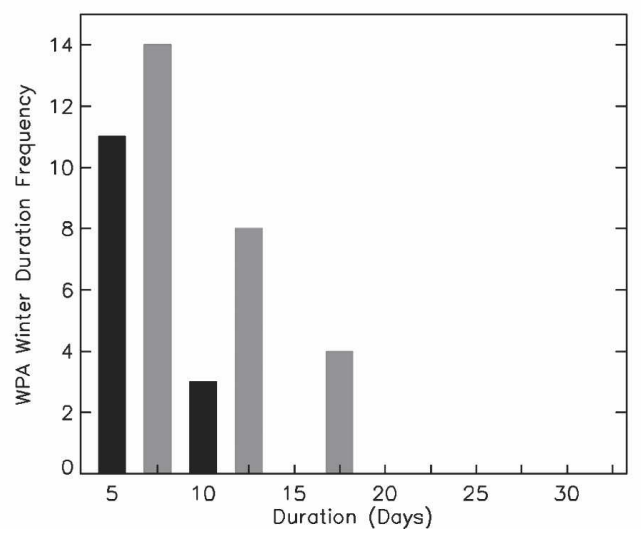

b

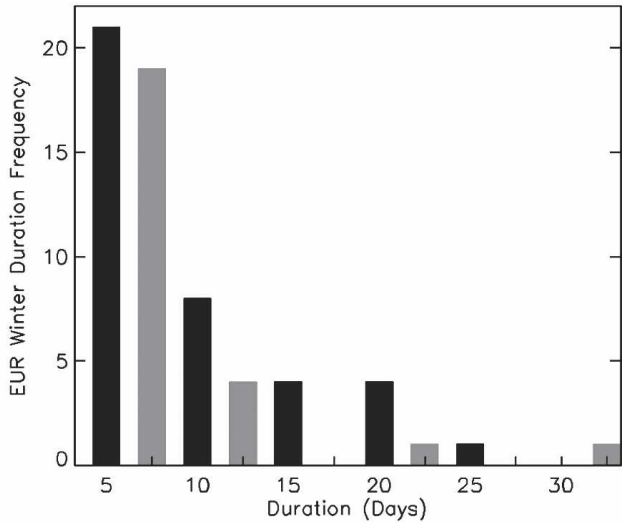

d

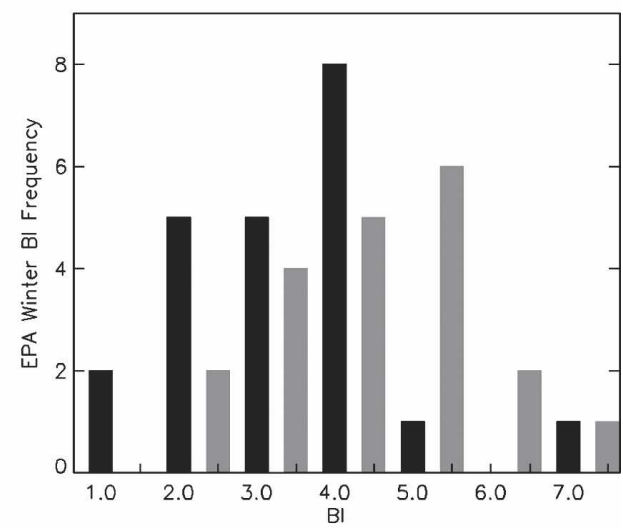

FIG. 10. Frequency distributions of (a) ATL winter blocking event durations for the positive (black bars) and the negative (light bars) phase of the NAO, (b) EUR winter blocking event durations for the positive (black bars) and the negative (light bars) phase of the SCAN, (c) WPA winter blocking event durations for the positive (black bars) and the negative (light bars) phase of the ENSO, and (d) EPA winter blocking intensities for the positive (black bars) and the negative (light bars) phase of the ENSO.

during the negative phase of the NAO. However, as demonstrated here, there was also a strong dependence between fall blocking occurrence and the NAO. Figure 11a displays the winter average distribution of blocking center frequency for the positive and the negative NAO phases. There was a significant $(p<0.01)$ northward displacement of almost $5^{\circ}(p<0.01)$ during the negative phases of the NAO for both winter and autumn as well as a westward extension of the averaged autumn and wintertime blocking locations of about $10^{\circ}(p<$ $0.1)$.

\section{2) EUROPEAN SECTOR}

The multiple regression analysis showed that the main SCAN influence during the winter season, with about $30 \%$ of the EUR blocking frequency explained variance. SCAN was also the dominant pattern during fall, but only accounting for $20 \%$ of the variance. Figure 9b displays the winter average blocked days frequency when SCAN was in the positive phase (solid line) and negative phase (dashed line). Winter positive phases of the SCAN reveal an average annual frequency of 36.5 blocked days, double that occurring for the negative phases $(14.6)(p<0.01)$. Also, when SCAN was in the positive phase, $30 \%$ longer blocking episodes were observed over Europe $(p<0.1)$ (Fig. 10b) and blocking center locations were on average $5^{\circ}$ northward $(p<$ $0.01)$ and $5^{\circ}$ eastward $(p<0.1)$ shifted toward inner Europe (see Fig. 11b).

\section{3) West Pacific Sector}

An examination of WPA blocking variability showed the WP pattern as the primary mode of variability during the whole year, being especially prominent during spring, when it explained about $25 \%$ of the blocking frequency variance. Significant differences $(p<0.01)$ 
a
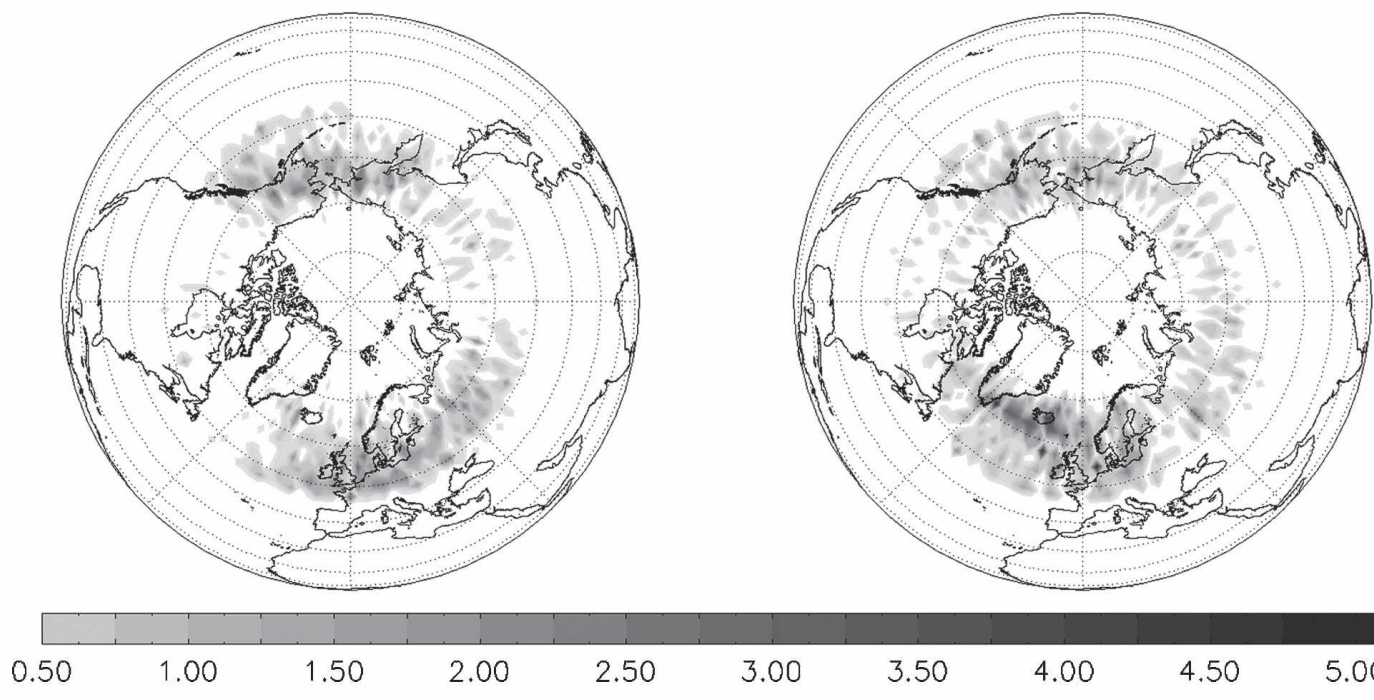

\subsection{0}

\subsection{0}

4.00

4.50

5.00

b
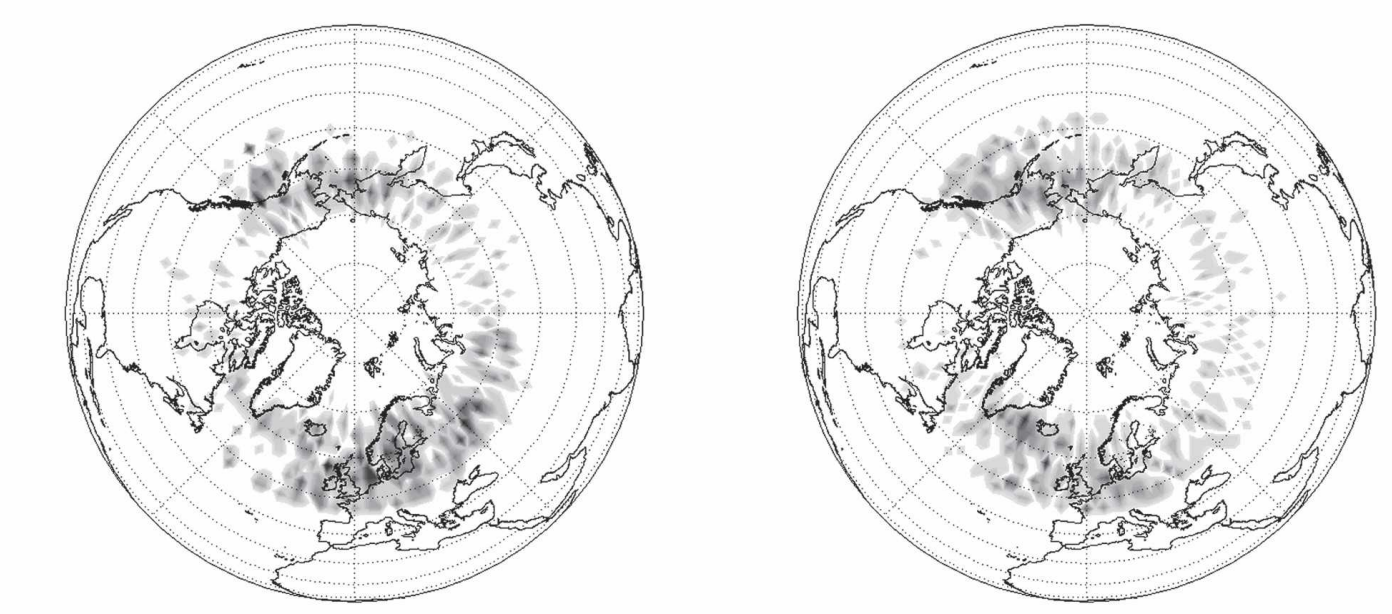

\subsection{0}

1.00

1.50

2.00

2.50

3.00

3.50

4.00

4.50

5.00

FIG. 11. Blocking center distribution for (left) the positive and (right) the negative phases of the (a) winter NAO, (b) winter SCAN, (c) spring WP, and (d) winter EP.

between blocking frequency in the positive and negative phases of the WP were found in spring, with values in the negative phase (16.2) being twice those of the positive phase (7.6; see Fig. 9c). However, differences in the persistence of blocking events here were not significant. It was the phase of the WP that determined pronounced zonal variations in the location and intensity of the Asian jet stream; when WP was in the negative phase more blocks were located in the eastern portion of the WPA sector $(p<0.1)$, with an averaged eastern displacement of almost $10^{\circ}$ in longitude (see Fig. 11c).

\section{4) East Pacific Sector}

The only relevant TCP influence on the EPA blocking frequency was limited to winter, when EP accounted for more than $35 \%$ of blocking variance. During the negative phase of EP the winter average number of blocked days in the EPA sector was 24.1, versus 8.6 days for the positive phase ( $p<0.01$; Fig. $9 d)$. Winter blocking events were also $15 \%$ larger during the negative phase of the EP, although the difference was not significant at $p<0.1$. Positive values of EP were associated with a pronounced northeastward extension 
C
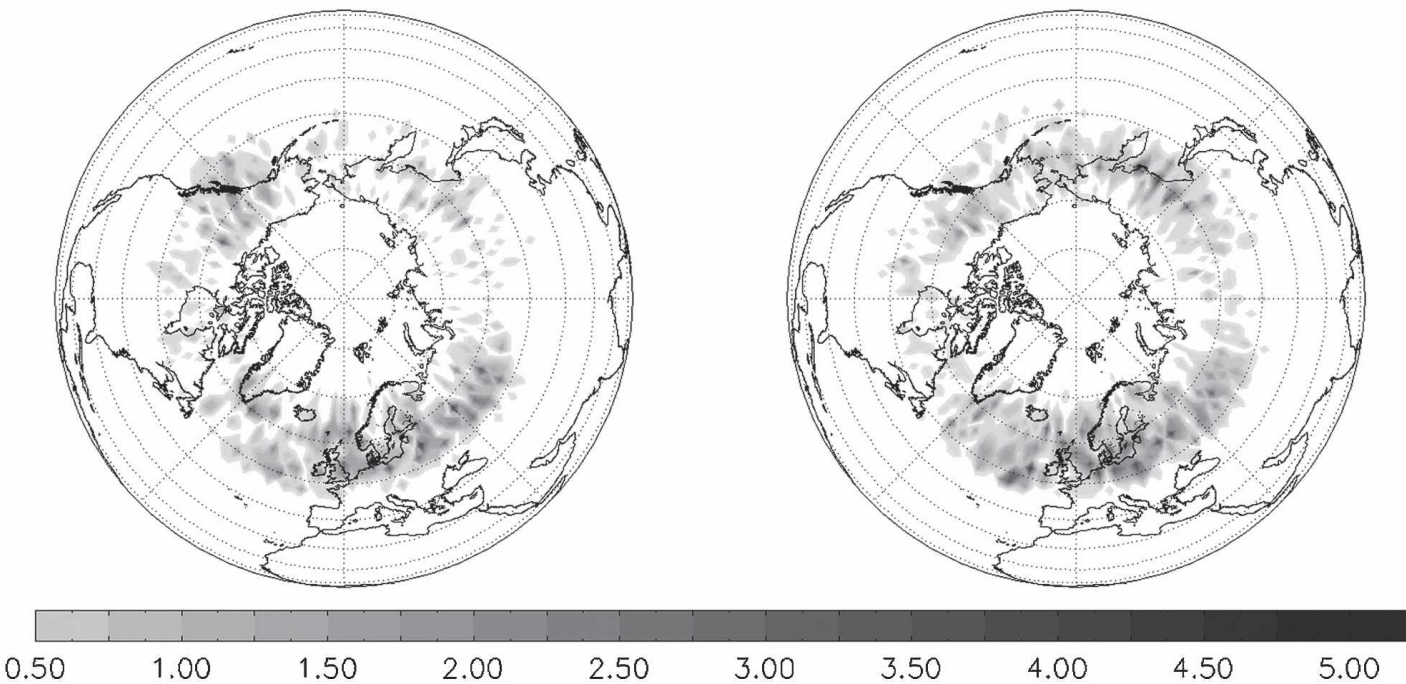

d

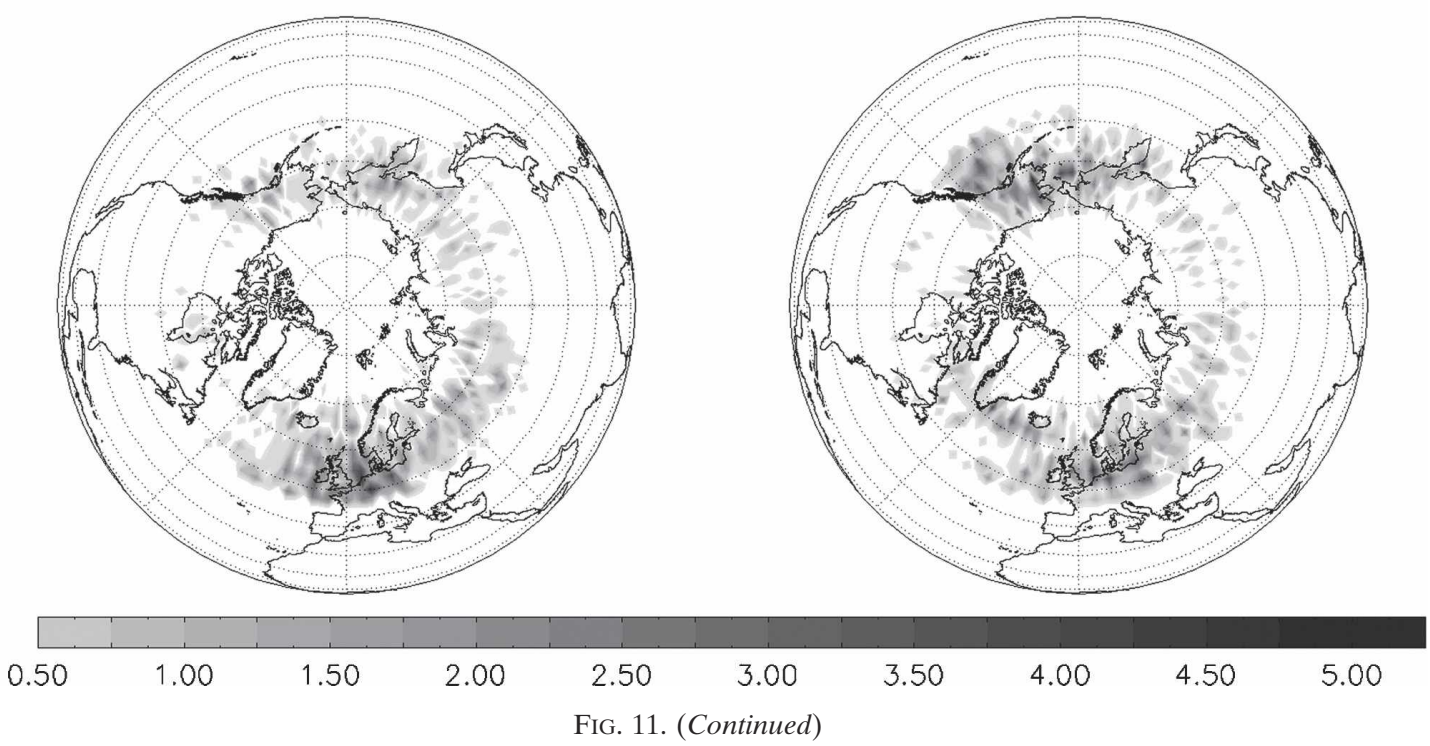

of the Pacific jet and enhanced westerlies over western North America. In contrast, during the negative phases, westerlies were reduced and the split-flow configuration over the North Pacific-favored blocking occurrence. Thus, blocks were more frequent over Alaska and Bering Strait (see Fig. 11d), and averaged blocking centers were $\left(8^{\circ}\right)$ westward displaced $(p<0.1)$ when EP was in the negative phase.

\section{5) ENSO-RELATED VARIABILITY}

The ENSO cycle exhibits a strong influence on blocking intensities and durations, especially in winter and over the EPA and WPA sectors, with longer and more intense blocking events when La Niña (LN) was dom- inant. The averaged winter blocking intensity during a LN phase was 3.2 for the whole Northern Hemisphere, whereas when the ENSO was in a warm phase, the winter mean was 2.7 , the difference being significant at $p<0.01$. By winter season sectors, the ATL, EUR, WPA, and EPA blocks were 14\% $(p<0.05), 15 \%$ $(p<0.05), 16 \%(p<0.05)$, and $52 \%(p<0.01)$ stronger during LN, respectively, in agreement with those results reported by WI02 (Fig. 10d). Also, blocking events were $23 \%(42 \%)$ larger over the WPA (EPA) sector for LN ( $p<0.05$; Fig. 10c). These results were consistent with those reported by Renwick and Wallace (1996). They found smaller 500-hPa variances during El Niño (EN) years, implying more zonal flow and en- 
hanced westerlies over the North Pacific. Since BI is proportional to meridional height gradients, it implies that higher intensities occur during LN phases (WI02).

\section{Discussion}

\section{a. The ENSO influence on blocking}

The cold phase of the ENSO has been often associated with an increase of blocking occurrence, especially over the Pacific sector and Bering Strait in winter (Renwick and Wallace 1996) where higher frequencies have been found during the La Niña phase. WI02 also found relatively more blocked days during $\mathrm{LN}$ phases, especially over the Pacific sector, although differences in blocking occurrence were not significant. However, our analysis did reveal significant differences related to the ENSO in the frequency of EPA or WPA blocked days. These discrepancies may be attributed to the higher regional resolution of blocking sectors considered here. Another explanation could be related to the ENSO influence in determining preferred blocking formation locations, but not blocking occurrences.

A Student's $t$ test applied to the blocking frequencies revealed more westward blocked days during the cool phase of the ENSO relative to those occurring during EN phases over the Pacific (Fig. 9e). Thus, when the ENSO in is the LN phase, blocking occurrence is westward displaced and fewer blocks occur over the EPA sector. Simultaneously, a similar increase of blocking frequencies was found in the WPA sector without any significant frequency change over the whole Pacific. In fact, WPA blocked days increase during the LN phase, while the EPA sector presents more blocked days during EN years, although these results were not significant at $p<0.1$. Additionally, blocking center locations were displaced $10^{\circ}$ westward $(p<0.05)$ when ENSO was in the LN phase. These results are in agreement with van Loon and Madden (1981), who found higher sea level pressures (SLPs) over North America during EN, implying that blocking may be favored over there, whereas in the North Pacific region the relationship was reversed with an enhanced Aleutian low during the warm phase of ENSO. Thus, the ENSO signal over the Pacific sector seems limited to determining favored regions susceptible of blocking formation but not to blocking frequencies, reflecting the nonlinear ENSO nature, consistent with LN patterns showing a nonopposite response to that of the EN. These results are in agreement with Mullen (1989), who, analyzing GCM simulations, found that the ENSO and SST anomalies do not affect blocking frequency but the preferred locations for block formation over the Pacific region.

\section{b. The dynamic role of TCPs in blocking occurrence}

Several theories have been proposed on formation and maintenance of blocking events. Some of them are based on nonlinear interactions either between planetary waves (Egger 1978; Kung et al. 1990) or between large-scale flow and transient eddies (Reinhold and Pierrehumbert 1982). Other theories stress the role of amplified Rossby waves due to barotropic (Simmons et al. 1983) or baroclinic (Frederiksen 1982) instability. A number of these proposed that blocks may be the result of the adjustment of the planetary waves to deviations in the zonal mean flow (Kaas and Branstator 1993), or the linear resonance of planetary waves with the surface forcing (Tung and Lindzen 1979a,b). Additionally, conceptual models link low-frequency transient eddies and blocking events (Shutts 1983; Tsou and Smith 1990). Recently, Shabbar et al. (2001) demonstrate the decisive contribution of the NAO to the wintertime blocking occurrence over the Atlantic sector, establishing a simple conceptual model based on the Charney and DeVore (1979) theory. According to this theory, the blocking phenomenon can be a metastable equilibrium state between two equilibrium solutions of highindex flow (weak like-wave component) and low-index flow (strong wave component). Additionally, in the view of Charney and DeVore (1979), stable states can be considered in a regional context, and they view studies that consider blocking regional consistent with their own studies. Additionally, both topographical and thermal forcing between land continents and oceans are responsible in determining one or another stable solution. These views are consistent with the findings of Lupo et al. (2005) in that they find blocking events persist as long as the planetary-scale flow is quasi stable. However, when the planetary-scale flow evolves into a new phase, blocking events may no longer be supported. Also, Lupo (1997) demonstrates dynamically the independence of blocking regionally. Shabbar et al. (2001) offer a dynamical explanation relating the NAO, blocks, and the zonally asymmetric thermal forcing as induced by the land-sea temperature contrast. The phase of the NAO determines the land-sea zonal temperature distribution, favoring or inhibiting the resonance interaction phase between topographic and thermal forcing and, hence, the greater or lower occurrence of blocks.

Following this model, surface air temperature (SAT) composites have been computed for both polarities of the significant TCP from the monthly surface air temperature fields of the National Centers for Environmental Prediction-National Center for Atmospheric 
a

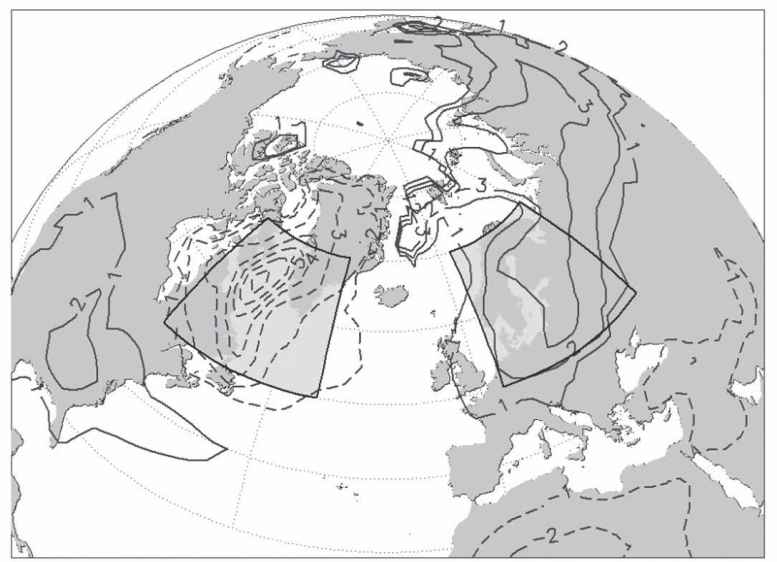

c

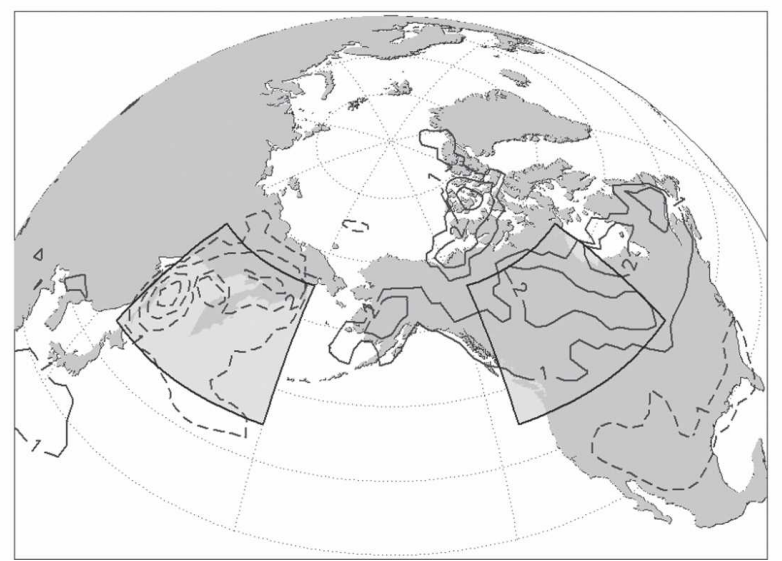

b

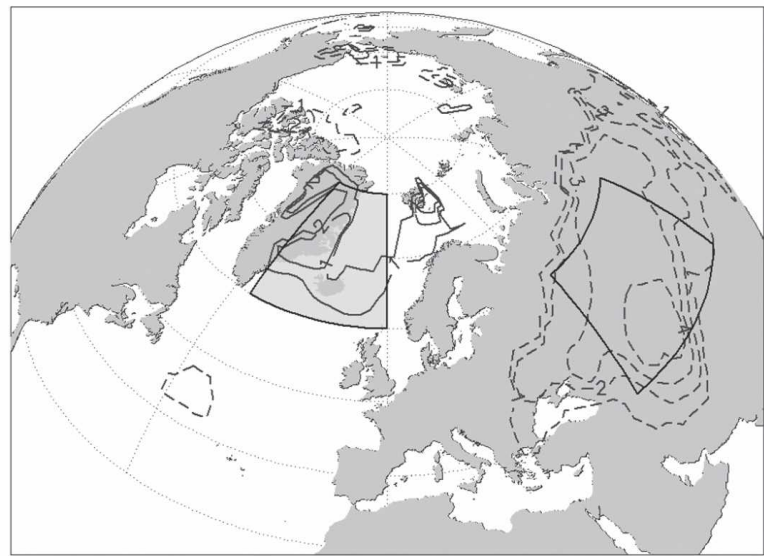

d

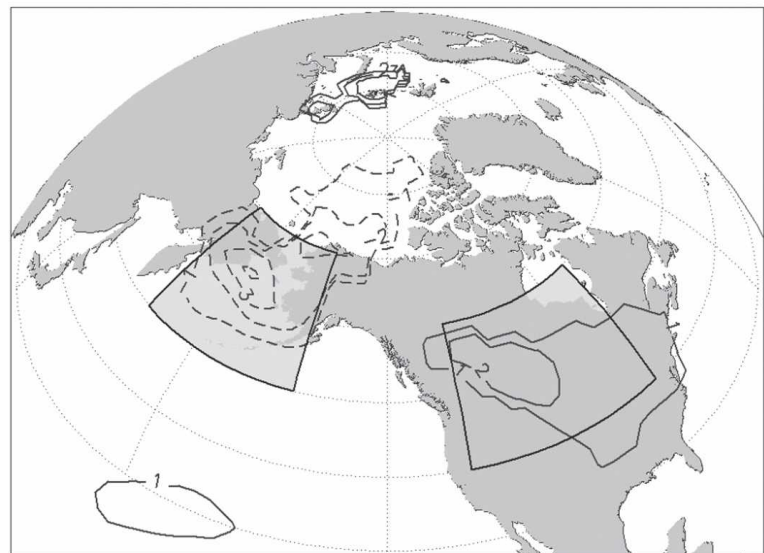

FIG. 12. Wintertime difference of SAT composites between the positive and negative phases of the (a) NAO, (b) SCAN, (c) WP, and (d) EP patterns. Those pairs of regions of maximum anomalous SAT responses for each TCP are marked with black solid lines.

Research (NCEP-NCAR) reanalysis, and their differences have been examined through a Student's $t$ test ( $p$ $<0.05)$. Figure 12 shows the composite difference of SAT between positive and negative phases of the NAO, SCAN, WP, and EP patterns in winter when the TCP influence on blocking frequency is relevant. The associated patterns reflect a temperature dipole of opposite sign over land and ocean such that, when the pattern is in the phase favoring the blocking occurrence, a general contrast "warm ocean/cold land" pattern is dominant. For the ATL sector and a negative phase of the NAO, the warming is located over Baffin Bay and the Labrador Sea, while a general cooling occurs over the north European and Asian continents. On the other hand, when the SCAN is in positive polarity, a pronounced cooling affects inland Europe accompanied by a relative warming over the North Sea and Greenland. The positive EP pattern reflects a thermal dipole with positive anomalies inland over North America and negative over Bering Strait. Thus, winter blocking variability is coherent with the conceptual model proposed by Charney and DeVore (1979) and Shabbar et al. (2001), linking blocking occurrence and dynamical TCP forcings in ATL, EUR, and EPA sectors. According to the conceptual model, over these sectors the zonally asymmetric thermal and topography forcing are in phase when the warm ocean/cold land pattern occurs, in the sense that the thermal forcing is coupled with the topography producing a favorable environment for the formation and persistence of blocking (Shabbar et al. 2001).

Additionally, the winter WP signature is characterized by above-normal temperatures over the eastern coast of Asia and simultaneous below-normal SATs spanning the North American continent during the negative phase of WP. In agreement with the concep- 
a

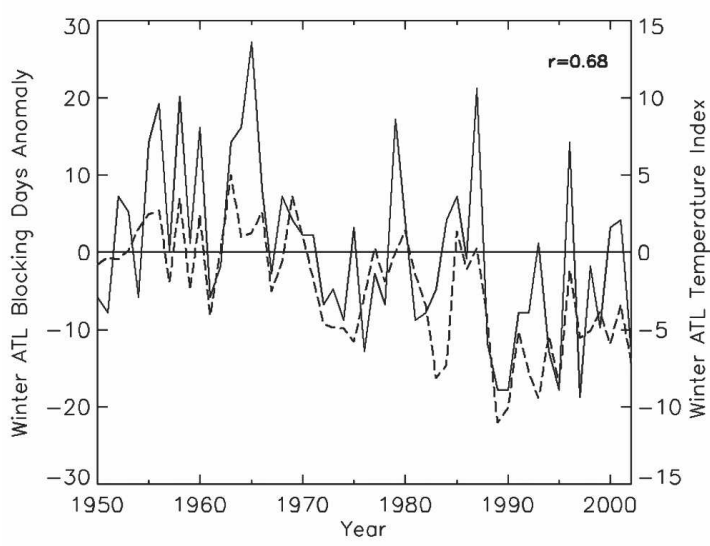

c

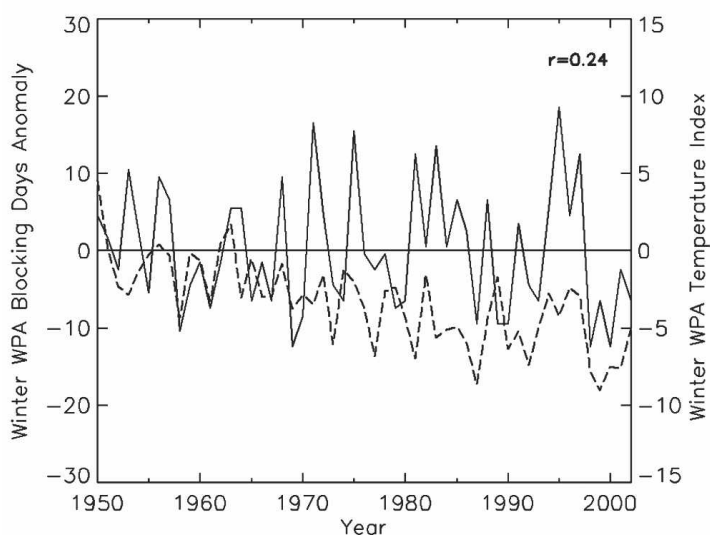

b

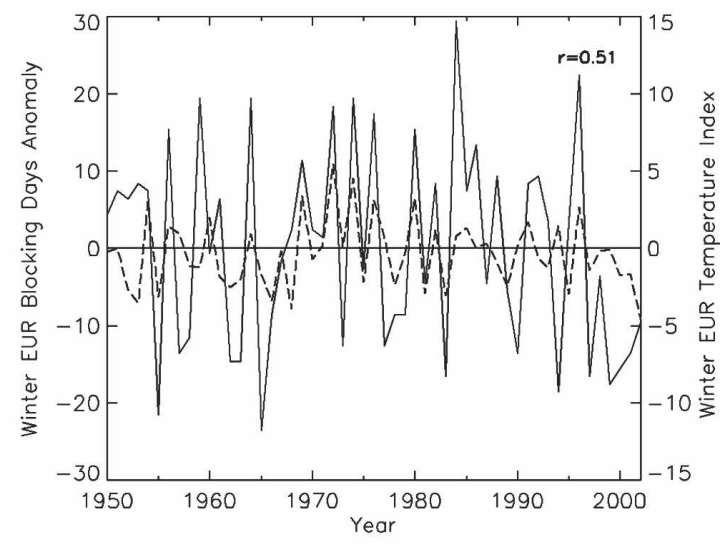

$\mathrm{d}$

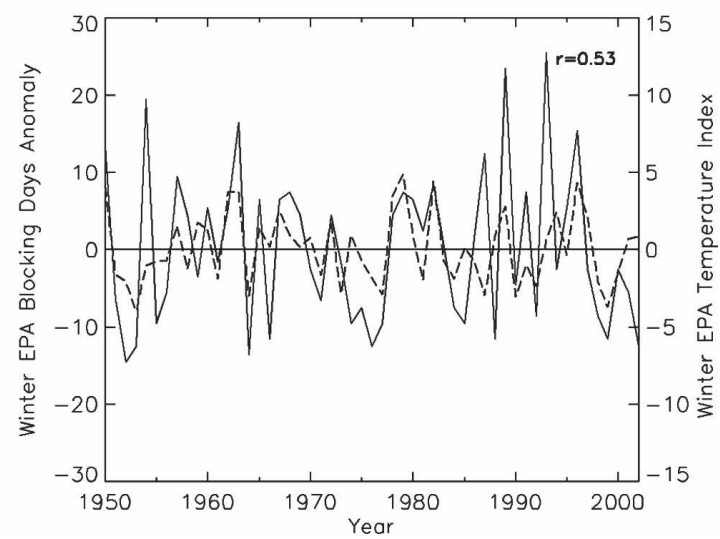

FIG. 13. Temporal series of winter anomalous blocking days frequency (solid line) and the $\Delta$ (SAT) index (dashed line) for the (a) ATL, (b) EUR, (c) WPA, and (d) EPA sectors. The correlation coefficient is indicated on the upper right-hand corner.

tual model, the zonally asymmetric thermal forcing should favor winter WPA blocking occurrences during the negative phases of WP. However, only $14 \%$ of WPA blocking frequency variance was accountable for the WP pattern in winter in the stepwise regression.

To provide an explanation of these different patterns pairs of oceanic-continental regions have been selected as in Fig. 12. They are defined $20^{\circ}$ in latitude and $40^{\circ}$ in longitude based on those areas of maximum positive and negative SAT responses of Fig. 12. For each TCP and blocking sector, a seasonal temperature index is defined as the box-averaged SAT differences between those boxes located over the respective oceanic and land regions,

$$
\Delta(\mathrm{SAT})_{S}=\left(\overline{\mathrm{SAT}}_{S}^{\mathrm{Oc}}-{\overline{\mathrm{SAT}_{S}^{\mathrm{Co}}}}^{\mathrm{Co}},\right.
$$

where the subindex $S$ represents the sector and the superindex $\mathrm{Oc}(\mathrm{Co})$ indicates the oceanic (continental) box. This index provides a measure of the average zonal air temperature difference between oceanic and continental regions. When linear correlations are computed between blocking days and winter $\Delta$ (SAT) indices, the magnitude of the link reaches $0.68,0.51$, and $0.53(p<0.01)$ for ATL, EUR, and EPA, respectively (Fig. 13). These results confirm that the associated TCPs (NAO, SCAN, and EP, respectively) exert a potential control in blocking atmospheric circulation by inducing anomalous longitudinal gradients of surface temperature. These land-sea contrasts may influence blocking occurrence through the temperatureassociated formation of anomalous zonal wind gradients. However, the correlation coefficient falls to 0.24 (not significant) for the WPA sector, suggesting a characteristic blocking behavior over the WPA sector. This is consistent with the findings of Nakamura et al. (1997) and Lupo (1997), who examined the relative contributions of large- and synoptic-scale processes in Pacific and Atlantic region blocking events. The long-term 
trend analysis provided in the last section also supports this assertion, with long-term WPA series presenting a significant trend in blocking frequency opposite in sign to the other regional trends. This distinctive behavior suggests that additional mechanisms may control the asymmetrical temperature distribution over the Eurasian sector more than the WP pattern. The dynamical link could be attributed to the unique surface conditions associated with thermal (Eurasian snow cover) and/or topographic (Himalayas) forcing mechanisms operating over the Asian continent. Anomalous North Pacific SST could act as a potential contributor to WPA blocking variability.

\section{c. Changes in atmospheric blocking}

The long-term analysis in blocking frequencies has shown a downward (upward) trend in blocking days over ATL and EUR (WPA) sectors. The observed changes over ATL and WPA are in concert with simultaneous changes in blocking occurrence, while the EUR trend is more related to significant decreases in blocking durations than in the number of blocking events. These results suggest that those observational trends could be partially explained by simultaneous changes in the forcing factors responsible for blocking formation (ATL and WPA) and maintenance (EUR), respectively.

In the context of the conceptual model discussed in the last section, regional modes have shown to modulate blocking occurrence through the anomalous TCPassociated temperature distributions. Thus, recent trends in surface temperature could be partially responsible for the observed trends in blocking occurrence.

Hurrell (1996) and Thompson et al. (2000) evaluated the contribution of the $\mathrm{NAO} / \mathrm{AO}$ to recent wintertime surface air temperature trends, with the NAO accounting for about $30 \%$ of the hemispheric interannual variance and about half of the cooling in the northwest of North America and the warming over Europe. Thus, the strong association between the NAO and blocking occurrence points to the recent upward NAO trend as a potential contributor to the observed decreasing trends in the ATL sector.

However, since the WP mode only accounts for a low percentage of WPA blocking occurrence, this pattern cannot explain the upward trend in WPA blocking occurrence. Indeed, the recent positive trend in the WP index is opposite to that expected, accordingly, to the increase of WPA blocking occurrence and the negative relationship between them.

On the other hand, the observed decreases in blocking days and durations over the EUR sector would be expected to result from significant changes in those mechanisms controlling blocking persistence. Several studies have shown the significant contribution of surface synoptic disturbances and explosive cyclogenesis westward from the block location in the maintenance of blocking events (Shutts 1983, 1986; Colucci 1985; Konrad and Colucci 1988; Tsou and Smith 1990; LS95). Simultaneously, relevant changes in North Atlantic storm-track activity that affect the western European sector have been found in winter (March) with significant decreases in cyclone densities near the Iberian Peninsula (Paredes et al. 2006).

However, further investigations on the mechanisms that maintain blocking, as well as on the forcing factors involved in WPA blocking, are required to provide more evidence of the observed trends over these sectors.

\section{Summary and conclusions}

In this paper, an automated algorithm method to detect blocking single structures and events has been developed, based on a modified version of the TM90 zonal index. The new methodology excludes those synoptic structures that do not reflect a typical blocking pattern and includes those blocks detected intermittently with some longitudes within the blocked anticyclone appearing as nonblocked. Additionally, some new parameters, such as blocking center location, size, and intensity, have been derived for a better characterization of blocked flow. The new methodology also includes a tracking algorithm. It allows a comprehensible assimilation and definition of blocking events and durations following individual evolution of single blocked flows. Some problems derived from the traditional methods when identifying persistent blocking (episodes) that could reflect different blocked flows are thus avoided.

The application of this objective algorithm has allowed the compilation of the longest blocking climatology for the Northern Hemisphere to date. This study provides robust results in a statistical sense, describing 55 years of blocking occurrences and parameters.

A new classification of blocking activity sectors has been proposed, providing a finer picture of regional blocking behavior. Four sectors (ATL, EUR, WPA, and EPA) have been defined according to different seasonal blocking distributions. The regional characterization shows that long-lasting events and greater extension and intensity were more common over oceanic sectors, especially in cold seasons, while blocking events were relatively more frequent over continental sectors in warm seasons.

This study shows that TCPs play a limited role in blocking occurrence. No TCP-related blocking variabil- 
ity has been found for the entire year, with the signal essentially confined to the winter season. In winter just one pattern appeared as the leading variability mode of blocking frequency over each region, all of them explaining more than $20 \%$ of variance, except in the WPA sector. Only the WPA sector revealed a significant signal in spring.

It has been found that regional blocking variability mostly reacts to their regional TCP counterparts, especially for frequency and duration parameters, supporting the blocking regional classification proposed in this paper. Thus, the primary TCP modulating blocking occurrences over the ATL, EUR, WPA and EPA sectors were, respectively, the NAO, SCAN, WP, and EP, although some slightly different season-related dependences have been found in the WPA sector. Unlike the rest of the sectors, the WPA did not show a leading mode in winter but in spring instead. Additionally, this study has shown that the ENSO influence was restricted to blocking intensities, with more intense blocking events occurring during the LN phase, especially over the EPA sector. On the other hand, no ENSO signals have been found in blocking sector frequency.

The link between TCPs and winter blocking occurrence has been attributed to the TCP-associated formation of anomalous longitudinal gradients in surface air temperature, identifying the surface forcing and the thermal land-sea contrast as a potential contributor to blocking occurrence variability at interannual and interdecadal scales. However, WPA variability was not coherent with the conceptual model proposed by Charney and DeVore (1979), suggesting that dynamical blocking mechanisms operating in the WPA may be different from those in the other sectors.

Acknowledgments. The Spanish Science and Technology Department supported this study trough the VALIMOD (Climatic Validation of Conceptual Models) project (REN2002-04558-C04-01).

\section{REFERENCES}

Austin, J. F., 1980: The blocking of middle latitude westerly winds by planetary waves. Quart. J. Roy. Meteor. Soc., 106, 327-350.

Barnston, A. G., and R. E. Livezey, 1987: Classification, seasonality and persistence of low-frequency atmospheric circulation patterns. Mon. Wea. Rev., 115, 1083-1126.

Charney, J. G., and J. G. DeVore, 1979: Multiple flow equilibria in the atmosphere and blocking. J. Atmos. Sci., 36, 1205-1216.

_ J. Shukla, and K. C. Mo, 1981: Comparison of a barotropic blocking theory with observation. J. Atmos. Sci., 38, 762-779.

Chen, T. C., and J. H. Yoon, 2002: Interdecadal variation of the North Pacific wintertime blocking. Mon. Wea. Rev., 130, 3136-3143.
Colucci, S. J., 1985: Explosive cyclogenesis and large-scale circulation changes: Implications for atmospheric blocking. $J$. Atmos. Sci., 42, 2701-2717.

_ , and T. L. Alberta, 1996: Planetary-scale climatology of explosive cyclogenisis and blocking. Mon. Wea. Rev., 124, 2509 2520.

d'Andrea, F., and Coauthors, 1998: Northern Hemisphere atmospheric blocking as simulated by 15 atmospheric general circulation models in the period 1979-1988. Climate Dyn., 14, 385-407.

Dole, R. M., and N. D. Gordon, 1983: Persistent anomalies of the extratropical Northern Hemisphere wintertime circulation: Geographical distribution and regional persistence characteristics. Mon. Wea. Rev., 111, 1567-1586.

Egger, J., 1978: Dynamics of blocking highs. J. Atmos. Sci., 35, $1788-1801$.

Elliot, R. D., and T. B. Smith, 1949: A study of the effect of large blocking highs on the general circulation in the northernhemisphere westerlies. J. Meteor., 6, 67-85.

Frederiksen, J. S., 1982: A unified three-dimensional instability theory of the onset of blocking and cyclogenisis. J. Atmos. Sci., 39, 969-987.

Hurrell, J. W., 1996: Influence of variations in extratropical wintertime teleconnections on Northern Hemisphere temperature. Geophys. Res. Lett., 23, 665-668.

Kaas, E., and G. Branstator, 1993: The relationship between a zonal index and blocking activity. J. Atmos. Sci., 50, 30613077.

Kalnay, E., and Coauthors, 1996: The NCEP/NCAR 40-Year Reanalysis Project. Bull. Amer. Meteor. Soc., 77, 437-471.

Kistler, R., and Coauthors, 2001: The NCEP-NCAR 50-year reanalysis: Monthly means CD-ROM and documentation. Bull. Amer. Meteor. Soc., 82, 247-268.

Konrad, C. E., and S. J. Colucci, 1988: Synoptic climatology of 500 $\mathrm{mb}$ circulation changes during explosive cyclogenesis. Mon. Wea. Rev., 116, 1431-1443.

Kung, E. C., C. C. DaCamara, W. E. Baker, J. Susskind, and C. K. Park, 1990: Simulations of winter blocking episodes using observed sea surface temperatures. Quart. J. Roy. Meteor. Soc., 116, 1053-1070.

Lejenäs, H., and H. Øakland, 1983: Characteristics of northern hemisphere blocking as determined from long time series of observational data. Tellus, 35A, 350-362.

Liu, Q., 1994: On the definition and persistence of blocking. Tellus, 46A, 286-290.

Lupo, A. R., 1997: A diagnosis of two blocking events that occurred simultaneously over the midlatitude Northern Hemisphere. Mon. Wea. Rev., 125, 1801-1823.

— anticyclones in the Northern Hemisphere. Tellus, 47A, 439456.

, R. J. Oglesby, and I. I. Mokhov, 1997: Climatological features of blocking anticyclones: A study of Northern Hemisphere CCM1 model blocking events in present-day and double $\mathrm{CO}_{2}$ concentration atmospheres. Climate Dyn., 13, 181-195.

- A. R. Kunz, and I. I. Mokhov, 2005: The impact of the planetary scale on the decay of blocking and the use of phase diagrams in examining the problem. Preprints, 21st Conf. on Weather Analysis and Forecasting, Washington, DC, Amer. Meteor. Soc., 1-7.

Mokhov, I. I., and E. A. Tikhonova, 2000: Atmospheric blocking characteristics in the Northern Hemisphere: Diagnostics of 
changes. Research Activities in Atmospheric and Ocean Modeling, WMO TD-987, 1 pp.

Mullen, S. L., 1989: Model experiments on the impact of Pacific sea surface temperature anomalies on blocking frequency. $J$. Climate, 2, 997-1013.

Nakamura, H., M. Nakamura, and J. L. Anderson, 1997: The role of high- and low-frequency dynamics in blocking formation. Mon. Wea. Rev., 125, 2074-2093.

Namias, J., and P. F. Clapp, 1951: Observational studies of general circulation patterns. Compendium of Meteorology, T. F. Malone, Ed., Amer. Meteor. Soc., 551-568.

Paredes, D., R. M. Trigo, R. García-Herrera, and I. F. Trigo, 2006: Understanding precipitation changes in Iberia in early spring: Weather typing and storm-tracking approaches. J. Hydrometeor., 7, 101-113.

Pelly, J., and B. Hoskins, 2003: A new perspective on blocking. $J$. Atmos. Sci., 60, 743-755.

Reinhold, B. B., and R. T. Pierrehumbert, 1982: Dynamics of weather regimes: Quasi-stationary waves and blocking. Mon. Wea. Rev., 110, 1105-1145.

Renwick, J. A., and J. M. Wallace, 1996: Relationships between North Pacific wintertime blocking, El Niño, and the PNA pattern. Mon. Wea. Rev., 124, 2071-2076.

Rex, D. F., 1950a: Blocking action in the middle troposphere and its effect upon regional climate. Part I: An aerological study of blocking action. Tellus, 2, 196-211.

_ 1950b: Blocking action in the middle troposphere and its effect upon regional climate. Part II: The climatology of blocking action. Tellus, 2, 275-301.

Schwierz, C., M. Croci-Maspoli, and H. C. Davies, 2004: Perspicacious indicators of atmospheric blocking. Geophys. Res. Lett., 31, L06125, doi:10.1029/2003GL019341.

Shabbar, A., J. Huang, and K. Higuchi, 2001: The relationship between the wintertime North Atlantic Oscillation and blocking episodes in the North Atlantic. Int. J. Climatol., 21, 355-369.

Shutts, G. J., 1983: The propagation of eddies in diffluent jet streams: Eddy forcing of "blocking" flow fields. Quart. J. Roy. Meteor. Soc., 109, 737-762.

_ 1986: A case study of eddy forcing during an Atlantic blocking episode. Advances in Geophysics, Vol. 29, Academic Press, $135-162$.

Simmons, A. J., J. M. Wallace, and G. W. Branstator, 1983: Barotropic wave propagation and instability, and atmospheric telleconnection patterns. J. Atmos. Sci., 40, 1363-1391.

Thompson, D. W. J., J. M. Wallace, and G. C. Hegerl, 2000: Annular modes in the extratropical circulation. Part II: Trends. J. Climate, 13, 1018-1036.
Tibaldi, S., and F. Molteni, 1990: On the operational predictability of blocking. Tellus, 42A, 343-365.

—, E. Tosi, A. Navarra, and L. Pedulli, 1994: Northern and Southern Hemisphere seasonal variability of blocking frequency and predictability. Mon. Wea. Rev., 122, 1971-2003.

_ , F. d'Andrea, E. Tosi, and E. Roeckner, 1997: Climatology of Northern Hemisphere blocking in the ECHAM model. Climate Dyn., 13, 649-666.

Treidl, R. A., E. C. Birch, and P. Sajecki, 1981: Blocking action in the Northern Hemisphere: A climatological study. Atmos.Ocean, 19, 1-23.

Trigo, R. M., I. F. Trigo, C. C. DaCamara, and T. J. Osborn, 2004: Winter blocking episodes in the European-Atlantic sector: Climate impacts and associated physical mechanisms in the Reanalysis. Climate Dyn., 23, 17-28.

Tsou, C. H., and P. J. Smith, 1990: The role of synoptic/planetaryscale interactions during the development of a blocking anticyclone. Tellus, 42A, 174-193.

Tung, K. K., and R. S. Lindzen, 1979a: A theory of stationary long waves. Part I: A simple theory of blocking. Mon. Wea. Rev., 107, 714-734.

$\longrightarrow$, and $-1979 \mathrm{~b}$ : A theory of stationary long waves. Part II: Resonant Rossby waves in the presence of realistic vertical shears. Mon. Wea. Rev., 107, 735-750.

van Loon, H., and R. A. Madden, 1981: The Southern Oscillation. Part I: Global associations with pressure and temperature in northern winter. Mon. Wea. Rev., 109, 1150-1162.

Verdecchia, M., G. Visconti, F. d'Andrea, and S. Tibaldi, 1996: A neural network approach for blocking recognition. Geophys. Res. Lett., 23, 2081-2084.

von Storch, H., and F. W. Zwiers, 1999: Statistical Analysis in Climatic Research. Cambridge University Press, 484 pp.

Wallace, J. M., and D. S. Gutzler, 1981: Teleconnections in the geopotential height field during the Northern Hemisphere winter. Mon. Wea. Rev., 109, 784-812.

Watson, J. S., and S. J. Colucci, 2002: Evaluation of ensemble predictions of blocking in the NCEP Global Spectral Model. Mon. Wea. Rev., 130, 3008-3021.

White, W. B., and N. E. Clark, 1975: On the development of blocking ridge activity over the central North Pacific. $J$. Atmos. Sci., 32, 489-502.

Whittaker, L. M., and L. H. Horn, 1981: Geographical and seasonal distribution of North American cyclogenesis, 19581977. Mon. Wea. Rev., 109, 2312-2322.

Wiedenmann, J. M., A. R. Lupo, I. I. Mokhov, and E. A. Tikhonova, 2002: The climatology of blocking anticyclones for the Northern and Southern Hemispheres: Block intensity as a diagnostic. J. Climate, 15, 3459-3473. 